LONG-TERM MEMORY IN STOCK MARKET PRICES

by

Andrew W. Lo

Latest Revision: May 1989

Working Paper No. 3014-89-EFA 


\title{
LONG-TERM MEMORY IN STOCK MARKET PRICES
}

\author{
Andrew W. Lo*
}

First Draft: March 1988

Latest Revision: May 1989

\begin{abstract}
A test for long-run memory that is robust to short-range dependence is developed. It is a simple extension of Mandelbrot's "range over standard deviation" or R/S statistic, for which the relevant asymptotic sampling theory is derived via functional central limit theory. This test is applied to daily, weekly, monthly, and annual stock returns indexes over several different time periods. Contrary to previous findings, there is no evidence of long-range dependence in any of the indexes over any sample period or sub-period once short-term autocorrelations are taken into account. Illustrative Monte Carlo experiments indicate that the modified $\mathrm{R} / \mathrm{S}$ test has power against at least two specific models of long-run memory, suggesting that stochastic models of short-range dependence may adequately capture the time series behavior of stock returns.
\end{abstract}

\footnotetext{
* Sloan School of Management, Massachusetts Institute of Technology, and NBER. I am grateful to Joseph Haubrich for stimulating my interest in this area and for many enlightening discussions. I also thank Buzs Brock, John Campbell, Lars Hansen, Bruce Lehmsnn, Craig MacKinlay, Pierre Perron, Jim Poterba, two referees, and seminar participants at the 1988 Johnson Biennial Symposium, the NBER-FMME 1988 Summer Institute, the Board of Governors of the Federal Reserve System, Columbia University, Harvard University, M.I.T., Queen's University, and the University of Pennsylvania for helpful comments. Research support from the National Science Foundation (Grant No. SES-8520054), the John M. Olin Fellowship at the NBER, the Rodney $L$. White Fellowship at the Wharton School, and the Univensity of Pennaylvania Research Foundation is gratefully acknowledged.
} 


\section{Introduction.}

That economic time series may exhibit long-range dependence has been a hypothesis of many early theories of the trade and business cycles. Such theories were often motivated by the distinct but non-periodic cyclical patterns that typified plots of economic aggregates over time. Economic data often display cycles of many periods, some that seem nearly as long as the span of the sample. In the frequency domain such time series are said to have power at the low frequencies. So common was this particular feature of the data that Granger (1966) dubbed it the "typical spectral shape of an economic variable," whereas Mandelbrot and Wallis (1968) used the more colorful term "Joseph Effect." 1

Nature's predilection towards long-range dependence has been well-documented in the natural sciences such as hydrology, meteorology, and geophysics and to the extent that the ultimate sources of economic uncertainty are natural phenomena like weather or sunspots, we might also expect long-term memory in economic time series. ${ }^{2}$ Among the first to have considered the impact of persistent statistical dependence in asset prices was Mandelbrot (1971), who argued that the random walk and martingale models of speculative prices may not be realizable through arbitrage in the presence of long-term memory. Since then, several empirical studies have lent further support to the possibility of such persistence in financial asset prices. For example, Greene and Fielitz (1977) claim to have found long-range dependence in the daily returns of many securities listed on the New York Stock Exchange. More recent investigations have uncovered anomalous behavior in long-horizon stock returns; ${ }^{3}$ alternately attributed to speculative fads and to time-varying conditional expected returns, these long-run swings may be further evidence of the Joseph Effect.

The presence of long-memory components in asset returns has important implications for many of the paradigms used in modern financial economics. For example, optimal consumption/savings and portfolio allocation decisions may become extremely sensitive to the investment horizon if stock returns were long-range dependent. Problems also arise in the pricing of derivative securities such as options and futures via

\footnotetext{
1 This refers to the passage in the Book of Genesis [Chapter 42] in which Joseph foretold the seven years of plenty followed by the seven years of famine that Egypt was to experience.

${ }^{2}$ See Haubrich and Lo (1989) for a more mundane theory of long-range dependence in economics.

${ }^{3}$ See DeBondt and Thaler (1985), Fama and French (1988), Jegadeesh (1988, 1989), and Poterba and Summers (1988) for example.
} 
martingale methods, since long-term memory is inconsistent with the martingale property. Traditional tests of the Capital Asset Pricing Model and the Arbitrage Pricing Theory are no longer valid since standard methods of statistical inference do not apply to time series displaying such persistence. The conclusions of more recent tests of "efficient" markets or stock market rationality also hang precariously on the presence or absence of these non-periodic cycles in asset returns. ${ }^{4}$

In this paper we test for such forms of long-range dependence using a simple generalization of a statistic first proposed by the English hydrologist Harold Edwin Hurst (1951). This statistic, called the "rescaled range" or "range over standard deviation" or "R/S" statistic, has subsequently been refined by Mandelbrot $(1972,1975)$ and others in several important ways. ${ }^{5}$ However, even its refinements cannot distinguish between short and long run dependence [in a sense to be made precise below], a severe shortcoming in applications of $\mathrm{R} / \mathrm{S}$ analysis to recent stock returns data since it is now well-known that such data display substantial short-range dependence. ${ }^{6}$ To be of general interest, an empirical investigation of long-term memory in stock returns must account for the presence of low-order autocorrelation. By modifying the rescaled range appropriately, we construct a test statistic that is robust to short-term dependence and apply it to daily, weekly, monthly, and annual stock market returns indexes over several different sample periods. In contrast to the findings of Greene and Fielitz (1977), we find no evidence of long-range dependence in the data for any sample period or sub-period once the effects of short run dependence are accounted for. Monte Carlo experiments indicate that the modified $\mathrm{R} / \mathrm{S}$ test has power against at least two particular models of long-run memory, suggesting that the time series behavior of stock returns may be adequately captured by more conventional stochastic models with short-range dependence.

The particular notions of short and long memory are defined in Section 2 and some illustrative examples are provided. Section 3 reviews the original rescaled range statistic and discusses its limitations. In Section 4 the modified $\mathrm{R} / \mathrm{S}$ statistic is presented and an asymptotic sampling theory is developed via functional central limit theory. The results of the empirical investigation are reported in Section 5, size and power issues are discussed in Section 6, and we conclude in Section 7.

\footnotetext{
Merton (1987) provides an excellent survey of the recent literature.

${ }^{5}$ See Mandelbrot and Taqqu (1979) and Mandelbrot and Wallis $(1968,1969 a-c)$.

See Lo and MacKinlay (1988).
} 


\section{Long-Range Versus Short-Range Dependence.}

To develop a method of detecting long-term memory the distinction between longrange and short-range statistical dependence must be made precise. One of the most widely used concepts of short-range dependence is the notion of "strong-mixing" due to Rosenblatt (1956), a measure of the decline in statistical dependence of two events separated by successively longer spans of time. Heuristically, a time series is strongmixing if the maximal dependence between any two events becomes trivial as more time elapses between them. ${ }^{7}$ By controlling the rate at which the dependence between past and future events declines, it is possible to extend the usual laws of large numbers and central limit theorems to dependent sequences of random variables. We adopt strongmixing as an operational definition of short-range dependence in our null hypothesis of Section 4.

Such mixing conditions have been used extensively by White (1982), White and Domowitz (1984), and Phillips (1987) for example to relax the assumptions that ensure consistency and asymptotic normality of various econometric estimators. As Phillips (1987) observes, these conditions are satisfied by a great many stochastic processes including all Gaussian finite-order stationary ARMA models. Moreover, the inclusion of a moment condition also allows for heterogeneously distributed sequences [such as those exhibiting unconditional heteroscedasticity], an especially important extension in view of the apparent instabilities of financial time series.

\subsection{An Example of Long-Range Dependence.}

In contrast to the short memory of "weakly dependent" [i.e., mixing] processes, natural phenomena often display long-term memory in the form of non-periodic cycles. This has lead several authors, most notably Mandelbrot, to develop stochastic

${ }^{7}$ Let $\left\{X_{t}(\omega)\right\}$ be a stochastic process on the probability space $(\Omega, \xi, P)$ and define:

$$
\alpha(A, B) \equiv \sup _{\{A \in A, B \in B\}}|P(A \cap B)-P(A) P(B)| \quad A \subset \xi, B \subset \xi
$$

The quantity $\alpha(A, B)$ is a measure of the dependence between the two $\sigma$-fields $A$ and $B$ in $₹$. Denote by $B$ : the Borel $\sigma$-field generated by $\left\{X_{0}(\omega), \ldots, X_{t}(\omega)\right\}$, i.e., $B_{t}: \equiv \sigma\left(X_{0}(\omega), \ldots, X_{t}(\omega)\right) \subset \mathcal{F}$. Define the coefficients $\alpha_{k}$ as:

$$
\alpha_{k} \equiv \sup _{j} \alpha\left(B_{-\infty}^{j}, B_{j+k}^{\infty}\right)
$$

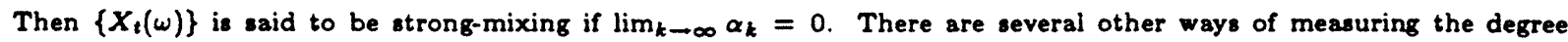
statistical dependence, giving rise to other notions of "mixing." For further details, see Rosenblatt (1956), White (1984), and the papers in Eberlein and Taqqu (1986). 
models that exhibit dependence even over very long time spans, such as the fractionallyintegrated time series models of Mandelbrot and Van Ness (1968), Granger and Joyeux (1980), and Hosking (1981). These stochastic processes possess autocorrelation functions that decay at much slower rates than those of weakly dependent processes, and violate the conditions of strong-mixing. For concreteness, let $X_{t}$ satisfy the following difference equation:

$$
(1-L)^{d} X_{t}=\epsilon_{t} \quad, \quad \epsilon_{t} \sim \mathrm{WN}\left(0, \sigma_{\epsilon}^{2}\right)
$$

where $L$ is the lag operator and $\epsilon_{t}$ is white noise. Granger and Joyeux (1980) and Hosking (1981) show that when the quantity $(1-L)^{d}$ is extended to non-integer powers of $d$ in the [mathematically] natural way, the result is a well-defined time series that is said to be "fractionally-differenced" [or, equivalently, "fractionally-integrated"]. Briefly, this involves expanding the expression $(1-L)^{d}$ via the binomial theorem for non-integer powers:

$$
(1-L)^{d}=\sum_{k=0}^{\infty}(-1)^{k}\left(\begin{array}{l}
d \\
k
\end{array}\right) L^{k},\left(\begin{array}{l}
d \\
k
\end{array}\right) \equiv \frac{d(d-1)(d-2) \cdots(d-k+1)}{k !}
$$

and then applying the expansion to $X_{t}$ :

$$
(1-L)^{d} X_{t}=\sum_{k=0}^{\infty}(-1)^{k}\left(\begin{array}{l}
d \\
k
\end{array}\right) L^{k} X_{t}=\sum_{k=0}^{\infty} A_{k} X_{t-k}=\epsilon_{t}
$$

where the AR coefficients $A_{k}$ are often re-expressed more compactly in terms of the gamma function:

$$
A_{k}=(-1)^{k}\left(\begin{array}{l}
d \\
k
\end{array}\right)=\frac{\Gamma(k-d)}{\Gamma(-d) \Gamma(k+1)}
$$

$X_{t}$ may also be viewed mechanically as an infinite-order MA process since: 


$$
X_{t}=(1-L)^{-d} \epsilon_{t}=B(L) \epsilon_{t} \quad, \quad B_{k}=\frac{\Gamma(k+d)}{\Gamma(d) \Gamma(k+1)}
$$

It is not obvious that such a definition of fractional-differencing might yield a useful stochastic process, but Granger (1980), Granger and Joyeux (1980), and Hosking (1981) show that the characteristics of fractionally-differenced time series are interesting indeed. For example, it may be shown that $X_{t}$ is stationary and invertible for $d \in\left(-\frac{1}{2}, \frac{1}{2}\right), 8$ and exhibits a unique kind of dependence that is positive or negative depending on whether $d$ is positive or negative; that is, the autocorrelation coefficients of $X_{t}$ are of the same sign as $d$. So slowly do the autocorrelations decay that when $d$ is positive their sum diverges to infinity, and collapses to zero when $d$ is negative. To develop a sense of this long-range dependence, compare the autocorrelations of a fractionallydifferenced $X_{t}$ with those of a stationary AR(1) in Table 1. Although both the AR(1) and the fractionally-differenced $\left[\mathrm{d}=\frac{1}{3}\right]$ series have first-order autocorrelations of 0.500 , at lag 25 the AR(1) correlation is 0.000 whereas the fractionally-differenced series has correlation 0.173 , declining only to 0.109 at lag 100 .

\subsection{A More Interesting Example.}

It is a simple matter to construct long-term memory processes with more realistic autocorrelation functions, ones that exhibit both positive and negative dependence at various lags. This is particularly relevant for stock returns since recent evidence suggests that short-horizon returns are positively autocorrelated whereas longer-horizon returns seem to display negative serial dependence. For example, Lo and MacKinlay (1988) show that the ratios of $k$-week stock return variances to $k$ times the variance of one-week returns generally exceed unity when $k$ is small [2 to 32]. However, Poterba and Summers (1988) find that this same variance ratio falls below one when $k$ is much larger [96 and greater].

Denote by $R_{t}$ the time-t return on a stock and let $R_{t}$ be the sum of two components $X_{t}$ and $Y_{t}$ where:

$$
(1-L)^{d} X_{t}=\epsilon_{t} \quad(1-\rho L) Y_{t}=\eta_{t}
$$

\footnotetext{
See, for example, Hosking (1981).
} 
and we choose the values $(-0.2,0.25,1,1.1)$ for the parameters $\left(d, \rho, \sigma_{\epsilon}^{2}, \sigma_{\eta}^{2}\right)$. Let the ratio of the $k$-period return variance to $k$ times the variance of $R_{t}$ be denoted by $\operatorname{VR}(k)$. Then a simple calculation will show that for the parameter values chosen:

$$
\begin{aligned}
\operatorname{VR}(2) & =1.04 & \operatorname{VR}(10) & =1.04 \\
\operatorname{VR}(3) & =1.06 & \operatorname{VR}(50) & =0.97 \\
\operatorname{VR}(4) & =1.07 & \operatorname{VR}(100) & =0.95 \\
\operatorname{VR}(5) & =1.06 & \operatorname{VR}(250) & =0.92
\end{aligned}
$$

The simple intuition for this pattern of variance ratios comes from observing that $\operatorname{VR}(k)$ is a weighted sum of the first $k-1$ autocorrelation coefficients of $R_{t}$ with linearly declining weights. ${ }^{9}$ When $k$ is small the autocorrelation of $R_{t}$ is dominated by the positively autocorrelated AR(1) component $Y_{t}$. But since the autocorrelations of $Y_{t}$ decay rapidly relative to those of $X_{t}$, as $k$ grows the influence of the long-memory component eventually outweighs that of the $\operatorname{AR}(1)$, ultimately driving the variance ratio below unity.

\section{The Classical $\mathbf{R} / \mathbf{S}$ Statistic.}

To detect long-range dependence [also called "strong dependence"], Mandelbrot has suggested using the range over standard deviation or $\mathrm{R} / \mathrm{S}$ statistic, also called the "rescaled range," which was developed by Hurst (1951) in his studies of river discharges. The $R / S$ statistic is the range of partial sums of deviations of a time series from its mean, rescaled by its standard deviation. Specifically, let $P_{t}$ denote the price of an asset at time $t$ and define $X_{t} \equiv \log P_{t}-\log P_{t-1}$ to be the continuously compounded single-period return of that asset from $t-1$ to $t$. We assume throughout that:

$$
X_{t}=\mu+\epsilon_{t} .
$$

${ }^{\circ}$ Specifically, if $\rho_{k}$ is the $k$-th order autocorrelation coefficient, then:

$$
\operatorname{VR}(k)=1+2 \sum_{j=1}^{k-1} \frac{k-j}{k} \rho_{j} .
$$


where $\mu$ is an arbitrary but fixed parameter. Consider a sample of returns $X_{1}, X_{2}, \ldots, X_{n}$ and let $\bar{X}_{n}$ denote the sample mean $\frac{1}{n} \sum_{j} X_{j}$. Then the classical re-scaled range statistic, which we shall call $\tilde{Q}_{n}$, is given by:

$$
\tilde{Q}_{n} \equiv \frac{1}{s_{n}}\left[\operatorname{Max}_{1 \leq k \leq n} \sum_{j=1}^{k}\left(X_{j}-\bar{X}_{n}\right)-\operatorname{Min}_{1 \leq k \leq n} \sum_{j=1}^{k}\left(X_{j}-\bar{X}_{n}\right)\right]
$$

where $s_{n}$ is the usual [maximum likelihood] standard deviation estimator:

$$
s_{n} \equiv\left[\frac{1}{n} \sum_{j}\left(X_{j}-\bar{X}_{n}\right)^{2}\right]^{1 / 2}
$$

The first bracketed term in (3.2) is the maximum [over $k$ ] of sum of the first $k$ deviations of $X_{j}$ from its sample mean. Since the sum of all $n$ deviations of $X_{j}$ 's from their mean is zero, this maximum is always non-negative. The second term in (3.2) is the minimum [over $k$ ] of this same sequence of partial sums, hence it is always non-positive. The difference of the two quantities, called the "range" for obvious reasons, is always nonnegative hence $\tilde{Q}_{n} \geq 0$.

The behavior of $\tilde{Q}_{n}$ may be better understood by considering its origins in hydrological studies of reservoir design. To accommodate seasonalities in riverflow, a reservoir's capacity must be chosen to allow for fluctuations in the supply of water above the dam while still maintaining a relatively constant flow of water below the dam. Since dam construction costs are immense, the importance of estimating the reservoir capacity necessary to meet long term storage needs is apparent. The range is an estimate of this quantity. If $X_{j}$ is the riverflow [per unit time] above the dam and $\bar{X}_{n}$ is the desired riverflow below the dam, the bracketed quantity in (3.2) is the capacity of the reservoir needed to ensure this smooth flow given the pattern of flows in periods 1 through $n .{ }^{10}$ This is most readily appreciated through a simple four-period numerical example in which we assume the riverflows to be 100,50,100, and 50 per year. If a constant annual flow of 75 below the dam is desired each year, a reservoir must have a minimum total capacity of 25 since it must store 25 units in years 1 and

\footnotetext{
${ }^{10}$ If some other smoothed flow $Z_{n}$ is desired below the dam in each of the $n$ periods, (3.2) still yieids the necessary capacity if $\bar{X}_{n}$ is replaced by $Z_{n}$.
} 
3 to provide for the relatively dry years 2 and 4. Now suppose the natural pattern of riverflow is $100,100,50,50$. To ensure a flow of 75 below the dam in this case, the minimum capacity must increase to 50 so as to accommodate the excess storage needed in years 1 and 2 to supply water during the "dry spell" in years 3 and 4 . Seen in this context, it is clear that an increase in persistence will increase the required storage capacity as measured by the range. Indeed, it was the apparent persistence of "dry spells" in Egypt that sparked Hurst's life-long fascination with the Nile, leading eventually to his interest in the rescaled range. ${ }^{11}$

In several seminal papers Mandelbrot, Taqqu, and Wallis demonstrate the superiority of $\mathrm{R} / \mathrm{S}$ analysis to more conventional methods of determining long-range dependence [such as autocorrelation analysis, spectral analysis, and variance ratios]. ${ }^{12}$ However, the rescaled range is also sensitive to short-range dependence. To see how, suppose the null hypothesis is that $\left\{X_{j}\right\}$ is an independently and identically distributed sequence. Then it is well-known [and is a special case of Theorem 3.1 below] that as $n$ increases without bound, the rescaled range converges in distribution to a well-defined random variable $V$ when properly normalized, i.e.,

$$
\frac{1}{\sqrt{n}} \tilde{Q}_{n} \Rightarrow V
$$

where ' $\Rightarrow$ ' denotes weak convergence and $V$ is the range of a Brownian bridge on the unit interval. ${ }^{13}$ If $\left\{X_{j}\right\}$ were generated by a long-range dependent process, the behavior of $\tilde{Q}_{n}$ would not be consistent with (3.4). Therefore, a test of the null hypothesis may be conducted by computing $\tilde{Q}_{n}$ and checking the compatibility of the point estimate with the theoretical distribution of $V$. But suppose, instead, that $\left\{X_{j}\right\}$ were generated by a stationary $\operatorname{AR}(1):{ }^{14}$

$$
X_{t}=\rho X_{t-1}+\epsilon_{t} \quad, \quad \epsilon_{t} \sim \mathrm{WN}\left(0, \sigma_{\epsilon}^{2}\right), \quad|\rho| \in(0,1) .
$$

\footnotetext{
11 The rescaled range was not Hurst's primary contribution to hydrology since the origin of the range statistic may be traced back to Rippl $(1883)$. The importance of Hurst's $(1951,1956)$ papers lies in his then startling discovery that the rescaled range grows as $n^{H}$ where $H$ is between 0.6 and 0.8 for hydrological applications. At the time, virtually all time series models predicted an $H$ of $\frac{1}{2}$.

${ }^{12}$ Mandelbrot (1972, 1975), Mandelbrot and Taqqu (1979), and Mandelbrot and Wallis (1968, 1969a-c).

${ }^{13}$ See Billingsley (1968) for the definition of weak convergence. We discuss the Brownian bridge and $V$ more formally in Section 4.

14 It is implicitly assumed throughout that white noise has a Lebesgue-integrable characteristic function to avoid the pathologies of Andrews (1984).
} 
Although (3.5) is short-range dependent, it yields a $\tilde{Q}_{n}$ that does not satisfy (3.4). In fact, it may readily be shown that for a stationary $\operatorname{AR}(1)$ the limiting distribution of $\tilde{Q}_{n} / \sqrt{n}$ is $\xi V$ where $\xi \equiv \sqrt{(1+\rho) /(1-\rho)} \cdot{ }^{15}$ For some portfolios of common stock $\hat{\rho}$ is as large as 50 percent, ${ }^{16}$ implying that the mean of $\tilde{Q}_{n} / \sqrt{n}$ may be biased upward by 73 percent! Since the mean of $V$ is $\sqrt{\frac{\pi}{2}} \approx 1.25$, the mean of the classical rescaled range would be 2.16 for such an AR(1) process. Using the critical values of $V$ reported in Table $2 a$, it is evident that a value of 2.16 would yield a rejection of the null hypothesis at any conventional significance level. This is not surprising since the values in Table $2 \mathrm{a}$ correspond to the distribution of $V$, not $\xi V$. Of course, by taking into account the "short-term" autocorrelations of the $X_{j}$ 's we may restore convergence to $V$. But this requires knowing the data-generating process which would eliminate the need for testing altogether.

Although aware of the effects of short-range dependence on the rescaled range, Mandelbrot $(1972,1975)$ did not correct for this bias since his focus was the relation of the R/S statistic's logarithm to the logarithm of the sample size as the sample size increases without bound. For short-range dependent time series such as strong-mixing processes the ratio $\log \tilde{Q}_{n} / \log n$ approaches $\frac{1}{2}$ in the limit, but converges to quantities greater or less than $\frac{1}{2}$ according to whether there is positive or negative long-range dependence. The limit of this ratio is often denoted by $H$ and is called the "Hurst" coefficient. ${ }^{17}$ Mandelbrot suggests estimating the Hurst coefficient by plotting the logarithm of $\tilde{Q}_{n}$ against the logarithm of the sample size $n$; beyond some large $n$, the slope of such a plot should settle down to $H .{ }^{18}$ However, although $H=\frac{1}{2}$ across general classes of short-range dependent processes, the finite-sample properties of the estimated Hurst coefficient are not invariant to the form of short run dependence. For example, Davies and Harte (1987) show that even though the Hurst coefficient of a stationary Gaussian $\mathrm{AR}(1)$ is precisely $\frac{1}{2}$, the 5 percent Mandelbrot regression test rejects this null hypothesis 47 percent of the time for an autoregressive parameter of 0.3. Additional Monte Carlo evidence is reported in Section 6.

\footnotetext{
${ }^{15}$ See Proposition 4.1.

${ }^{16}$ See Lo and MacKinlay (1988).

${ }^{17}$ For the fractionally-differenced process (2.1) we have the simple relation: $H=d+1 / 2$.

18 These are the "pox diagrams" of Mandelbrot and Wallis (1969a).
} 


\section{The Modified R/S Statistic.}

To distinguish between long- and short-range dependence, we must modify the $\mathrm{R} / \mathrm{S}$ statistic so that its statistical behavior is invariant over a general class of short memory processes, but deviates for long memory processes. Since $X_{t}=\mu+\epsilon_{t}$, whether or not $X_{t}$ exhibits long-term memory depends on the properties of the sequence of disturbances $\left\{\epsilon_{t}\right\}$. The particular properties that comprise our null hypothesis of shortrange dependence are given in Section 4.1 and we derive the limiting behavior of the modified R/S statistic under this null in Sections 4.2 to 4.4.

\subsection{The Null Hypothesis.}

Our null hypothesis consists of the following assumptions for $\left\{\epsilon_{t}\right\}$ :

$$
E\left[\epsilon_{t}\right]=0 \text { for all } t
$$

$$
\begin{aligned}
& \sup _{t} E\left[\left|\epsilon_{t}\right|^{\beta}\right]<\infty \text { for some } \beta>2 \\
& 0<\sigma^{2}=\lim _{n \rightarrow \infty} E\left[\frac{1}{n}\left(\sum_{j=1}^{n} \epsilon_{j}\right)^{2}\right]<\infty
\end{aligned}
$$

(A4) $\left\{\epsilon_{t}\right\}$ is strong-mixing with mixing coefficients $\alpha_{k}$ that satisfy:

$$
\sum_{j=1}^{\infty} \alpha_{j}^{1-\frac{2}{\beta}}<\infty .
$$

Condition (A1) is standard. Conditions (A2) through (A4) are restrictions on the maximal degree of dependence and heterogeneity allowable while still permitting some form of the law of large numbers and the [functional] central limit theorem to obtain. Although condition $(A 2)$ rules out infinite variance marginal distributions of $\epsilon_{t}$ such as those in the stable family with characteristic exponent less than 2 , the disturbances may still exhibit leptokurtosis via time-varying conditional moments [e.g. conditional heteroscedasticity]. Moreover, since there is a trade-off between conditions (A2) and $(A 4)$, the uniform bound on the moments can be relaxed if the mixing coefficients decline faster than $(A 4)$ requires. ${ }^{19}$ For example, if we require $\epsilon_{t}$ to have finite absolute

\footnotetext{
10 See Herrndorf (1985). One of Mandelbrot's (1972) arguments in favor of R/S analysis is that finite second moments are not required. This is indeed the case if we are interested only in the almost sure convergence of the statistic. But since we wish to derive its limiting distribution for purposes of inference, a stronger moment condition is needed.
} 
moments of all orders [corresponding to $\beta \rightarrow \infty$ ], then $\alpha_{k}$ must decline faster than $1 / k$. However, if we restrict $\epsilon_{t}$ to have finite moments only up to order 4 then $\alpha_{k}$ must decline faster than $1 / k^{2}$. These conditions are discussed at greater length by Phillips (1987), to which we refer interested readers.

Although conditions $(A 1)-(A 4)$ have been widely cited in the recent literature, several other sets of assumptions might have served equally well as our short-range dependent null hypothesis. For example, if we assume $\left\{\epsilon_{t}\right\}$ to be stationary and ergodic, the moment condition $(A 2)$ can be relaxed and more temporal dependence than ( $A 4)$ is allowable. ${ }^{20}$ Whether or not the assumption of stationarity is a restrictive one for financial time series is still unsettled. There is ample evidence of changing variances in stock returns over periods longer than 5 years, but unstable volatilities can be a symptom of conditional heteroscedasticity which can manifest itself in stationary time series. Since the empirical evidence regarding changing conditional moments in asset returns is mixed, allowing for non-stationarities in our null hypothesis may still have value. Moreover, conditions $(A 1)-(A 4)$ may be weakened further, allowing for still more temporal dependence and heterogeneity, hence widening the class of processes contained in our null hypothesis. ${ }^{21}$

Conditions $(A 1)-(A 4)$ are also satisfied by many of the recently proposed stochastic models of persistence, such as those of Campbell and Mankiw (1987), Fama and French (1988), and Poterba and Summers (1988). Consequently, our null hypothesis of short-range dependence encompasses their notions of longer-term correlation. Although the distinction between dependence in the short-run and the long-run may appear to be a matter of degree, strongly dependent processes behave so differently from weakly dependent time series that the dichotomy proposed in our null seems most natural. For example, the spectral densities at frequency zero of strongly dependent processes are either unbounded or zero whereas they are non-zero and finite for processes included in our null. The partial sums of strongly dependent processes do not converge in distribution at the same rate as weakly dependent series. And graphically, their behavior is marked by cyclical patterns of all kinds, some that are virtually indistinguishable from trends.

\footnotetext{
${ }^{20}$ See Hall and Heyde (1980).

${ }^{21}$ Specifically, that the sequence $\left\{\epsilon_{\mathrm{e}}\right\}$ is strong-mixing may be replaced by the weaker assumption that it is a near-epoch dependent function of a strong-mixing process. See McLeish (1977) and Wooldridge and White (1988) for further details.
} 


\subsection{The Test Statistic.}

Given a sample of observations $X_{1}, X_{2}, \ldots, X_{n}$ the modified rescaled range, which we denote by $Q_{n}$, is defined as:

$$
Q_{n} \equiv \frac{1}{\hat{\sigma}_{n}(q)}\left[\operatorname{Max}_{1 \leq k \leq n} \sum_{j=1}^{k}\left(X_{j}-\bar{X}_{n}\right)-\operatorname{Min}_{1 \leq k \leq n} \sum_{j=1}^{k}\left(X_{j}-\bar{X}_{n}\right)\right]
$$

where

$$
\begin{aligned}
\hat{\sigma}_{n}^{2}(q) & \equiv \frac{1}{n} \sum_{j=1}^{n}\left(X_{j}-\bar{X}_{n}\right)^{2}+\frac{2}{n} \sum_{j=1}^{q} \omega_{j}(q)\left\{\sum_{i=j+1}^{n}\left(X_{i}-\bar{X}_{n}\right)\left(X_{i-j}-\bar{X}_{n}\right)\right\} \\
& =\hat{\sigma}_{x}^{2}+2 \sum_{j=1}^{q} \omega_{j}(q) \hat{\gamma}_{j} \quad, \quad \omega_{j}(q) \equiv 1-\frac{j}{q+1} \quad q<n .
\end{aligned}
$$

and $\hat{\sigma}_{x}^{2}$ and $\hat{\gamma}_{j}$ are the usual sample variance and autocovariance estimators of $X$.

$Q_{n}$ differs from $\tilde{Q}_{n}$ only in its denominator, which is the square root of a consistent estimator of the partial sum's variance. If $\left\{X_{t}\right\}$ is subject to short-range dependence, the variance of the partial sum is not simply the sum of the variances of the individual terms, but also includes the autocovariances. Therefore, the estimator $\hat{\sigma}_{n}(q)$ involves not only sums of squared deviations of $X_{j}$, but also its weighted autocovariances up to lag q. The weights $\omega_{j}(q)$ are those suggested by Newey and West (1987) and always yield a positive $\hat{\sigma}_{n}^{2}(q)$, an estimator of the spectral density function of $X_{t}$ at frequency zero using a Bartlett window. Theorem 4.2 of Phillips (1987) demonstrates the consistency of $\hat{\sigma}_{n}(q)$ under the following conditions:

$\left(A 2^{\prime}\right) \quad \sup _{t} E\left[\left|\epsilon_{t}\right|^{2 \beta}\right]<\infty$ for some $\beta>2$.

(A5) As $n$ increases without bound, $q$ also increases without bound such that $q \sim o\left(n^{1 / 4}\right)$. 
By allowing $q$ to increase with [but at a slower rate than] the number of observations $n$, the denominator of $Q_{n}$ adjusts appropriately for general forms of short-range dependence. Of course, although the conditions $\left(A 2^{\prime}\right)$ and $(A 5)$ ensure the consistency of $\hat{\sigma}^{2}(q)$, they provide little guidance in selecting a truncation lag $q$. Monte Carlo studies have shown that when $q$ becomes large relative to the sample size $n$, the finite-sample distribution of the estimator can be radically different from its asymptotic limit. ${ }^{22}$ However $q$ cannot be chosen too small since the autocovariances beyond lag $q$ may be substantial and should be included in the weighted sum. Therefore, the truncation lag must be chosen with some consideration of the data at hand. Andrews (1988) does provide a data-dependent rule for choosing $q$, however its minimax optimality is still based on an asymptotic mean-squared error criterion; little is known about how best to pick $q$ in finite samples. We report some suggestive Monte Carlo evidence in Section 6.

Since there are several other consistent estimators of the spectral density function at frequency zero, conditions $\left(A 2^{\prime}\right)$ and $(A 5)$ can be replaced with weaker assumptions if conditions $(A 1),(A 3)$, and $(A 4)$ are suitably modified. If, for example, $X_{t}$ is $m$ dependent [so that observations spaced greater than $m$ periods apart are independent], Hansen (1982, Lemma 3.2) shows that the spectral density and frequency zero may be estimated consistently with a finite number of [unweighted] autocovariances. ${ }^{23}$ Other alternatives may be found in Hannan (1970, chapter V.4).

\subsection{The Asymptotic Distribution of $Q_{n}$.}

To derive the limiting distribution of the modified rescaled range $Q_{n}$ under our null hypothesis, consider the behavior of the following standardized sum:

$$
W_{n}(\tau) \equiv \frac{1}{\sigma \sqrt{n}} S_{[n \tau]} \quad \tau \in[0,1]
$$

where $S_{k}$ denotes the partial sum $\sum_{j=1}^{k} \epsilon_{j}$ and $[n \tau]$ is the greatest integer less than or equal to $n \tau$. The sample paths of $W_{n}(\tau)$ are elements of the function space $D[0,1]$, the space of all real-valued functions on $[0,1]$ that are right-continuous and possess finite

\footnotetext{
22 See Lo and MacKinlay (1989).

${ }^{23}$ Hansen also requires stationarity, ergodicity, and some moment conditions.
} 
left limits. Under certain conditions it may be shown that $W_{n}(\tau)$ converges weakly to a Brownian motion $W(\tau)$ on the unit interval, and that well-behaved functionals of $W_{n}(\tau)$ converge weakly to the same functionals of Brownian motion. ${ }^{24}$ Since we apply these two results extensively in deriving the limiting distribution of $Q_{n}$, we state them here for reference:

Lemma 4.1. [Herrndorf (1984)] If $\left\{\epsilon_{t}\right\}$ satisfies assumptions (A1)-(A4) then as $n$ increases without bound, $W_{n}(\tau) \Rightarrow W(\tau)$.

Lemma 4.2. [Extended Continuous Mapping Theorem / $^{25}$ Let $h_{n}$ and $h$ be measurable mappings from $D[0,1]$ to itself and denote by $E$ the set of $x \in D[0,1]$ such that $h_{n}\left(x_{n}\right) \rightarrow h(x)$ fails to hold for some sequence $x_{n}$ converging to $x$. If $W_{n}(\tau) \Rightarrow W(\tau)$ and $E$ is of Wiener-measure zero, i.e. $P(W \in E)=0$, then $h_{n}\left(W_{n}\right) \Rightarrow h(W)$.

Armed with these results, the limiting distribution of the modified rescaled range may be derived in three easy steps, summarized in: ${ }^{26}$

Theorem 4.1. ${ }^{27}$ If $\left\{\epsilon_{t}\right\}$ satisfies assumptions $(A 1),\left(A 2^{\prime}\right),(A 3)-(A 5)$, then as $n$ increases without bound:

(a)

$$
\begin{aligned}
\operatorname{Max}_{1 \leq k \leq n} \frac{1}{\hat{\sigma}_{n}(q) \sqrt{n}} \sum_{j=1}^{k}\left(X_{j}-\bar{X}_{n}\right) & \Rightarrow \operatorname{Max}_{0 \leq \tau \leq 1} W^{\circ}(\tau) \equiv M^{\circ} \\
\operatorname{Min}_{1 \leq k \leq n} \frac{1}{\hat{\sigma}_{n}(q) \sqrt{n}} \sum_{j=1}^{k}\left(X_{j}-\bar{X}_{n}\right) & \Rightarrow \operatorname{Min}_{0 \leq \tau \leq 1} W^{\circ}(\tau) \equiv m^{\circ} \\
\frac{1}{\sqrt{n}} Q_{n} & \Rightarrow M^{\circ}-m^{\circ} \equiv V .
\end{aligned}
$$

Parts $(a)$ and $(b)$ of Theorem 4.1 follows from Lemmas 4.1, 4.2 and Theorem 4.2 of Phillips (1987), and shows that the maximum and minimum of the partial sum

\footnotetext{
${ }^{24}$ See Billingsley (1968) for further details.

25 See Billingsley (1968) for a proof.

${ }^{26}$ Mandelbrot (1975) derives similar limit theorems for the statistic $\bar{Q}_{n}$ under the more restrictive i.i.d. assumption, in which case the limiting distribution will coincide with that of $Q_{n}$. Since we wish to expand our null hypothesis to include weakly dependent disturbances, we extend his results via the more general functional central limit theorem of Herrndorf $(1984,1985)$.

${ }^{27}$ Proofs of theorems are provided in the Appendix.
} 
of deviations of $X_{j}$ from its mean converges to the maximum and minimum of the celebrated Brownian bridge $W^{\circ}(\tau)$ on the unit interval, also called "pinned" or "tieddown" Brownian motion because $W^{\circ}(0)=W^{\circ}(1)=0$. That the limit of the partial sums is a Brownian bridge is not surprising since the summands are deviations from the mean and must therefore sum to zero at $k=n$. Part $(c)$ of the theorem follows immediately from Lemma 4.2 and is the key result, allowing us to perform large sample statistical inference once the distribution function for the range of the Brownian bridge is obtained. Since the joint distribution of the maximum $M^{\circ}$ and minimum $m^{\circ}$ of the Brownian bridge is well-known [see Billingsley (1968)], the distribution function of their difference may be readily derived: ${ }^{28}$

Theorem 4.2. The distribution and density functions of $V \equiv M^{\circ}-\mathrm{m}^{\circ}$, denoted by $F_{V}(v)$ and $f_{V}(v)$ respectively, are given by:

$$
\begin{aligned}
& F_{V}(v)=1+2 \sum_{k=1}^{\infty}\left(k-4 k^{2} v^{2}\right) e^{-2(k v)^{2}} \\
& f_{V}(v)=4 v \sum_{k=1}^{\infty} k^{2}\left(4 k^{2} v^{2}-k-2\right) e^{-2(k v)^{2}} .
\end{aligned}
$$

Critical values for tests of any significance level are easily obtained from the simple expression (4.5) for $F_{V}$. The values most commonly used are reported in Table 2. The moments of $V$ may be readily computed from (4.6); a simple calculation shows that $E[V]=\sqrt{\frac{\pi}{2}}$ and $E\left[V^{2}\right]=\frac{\pi^{2}}{6}$, thus the mean and standard deviation of $V$ are approximately 1.25 and 0.27 respectively. Plots of $F_{V}$ and $f_{V}$ are given in Figure 1 along with Gaussian distribution and density functions with comparable mean and variance. The distribution of $V$ is positively skewed and most of its mass falls between $\frac{3}{4}$ and 2 .

\subsection{The Relation Between $Q_{n}$ and $\tilde{Q}_{n}$.}

Since $Q_{n}$ and $\tilde{Q}_{n}$ differ solely in how the range is normalized, the limiting behavior of our modified R/S statistic and Mandelbrot's original will only coincide when

\footnotetext{
${ }^{28}$ Feller (1951) obtains similar results under the more restrictive assumption of i.i.d. disturbances.
} 
$\hat{\sigma}_{n}(q)$ and $s_{n}$ are asymptotically equivalent. From the definitions of $\hat{\sigma}_{n}(q)$ and $s_{n}$, it is apparent that the two will generally converge in probability to different limits in the presence of autocorrelation. Therefore, under the weakly dependent null hypothesis the statistic $\tilde{Q}_{n} / \sqrt{n}$ will converge to the range $V$ of a Brownian bridge multiplied by some constant. ${ }^{29}$ More formally, we have the almost trivial result:

Proposition 4.1. Under assumptions $(A 1)-(A 4), \tilde{Q}_{n} \Rightarrow \xi V$ where:

$$
\xi^{2} \equiv \frac{\lim _{n \rightarrow \infty} E\left[\frac{1}{n}\left(\sum_{j=1}^{n} \epsilon_{j}\right)^{2}\right]}{\lim _{n \rightarrow \infty} E\left[\frac{1}{n} \sum_{j=1}^{n} \epsilon_{j}^{2}\right]} .
$$

Therefore, normalizing the range by $s_{n}$ in place of $\hat{\sigma}_{n}(q)$ changes the limiting distribution of the rescaled range by the multiplicative constant $\xi$. This result was used in Section 3 to derive the limiting distribution of $\tilde{Q}_{n}$ in the AR(1) case.

Despite its sensitivity to short-range dependence, the classical $\mathrm{R} / \mathrm{S}$ statistic may still be used to test for independently and identically distributed $X_{t}$ 's; indeed, the AR(1) example of Section 3 and the results of Davies and Harte (1987) suggest that such a test may have considerable power against non-i.i.d. alternatives. However, since there is already a growing consensus among financial economists that stock market prices are not i.i.d., this null hypothesis is of less immediate interest. For example, it is now well-known that aggregate stock market returns exhibit significant serial dependence for short-horizon holding periods and are therefore not independently distributed. Since it is robust to many forms of heterogeneity and weak dependence, tests based on the modified R/S statistic $Q_{n}$ covers a broader set of null hypotheses than those using $\tilde{Q}_{n}$. More to the point, the modified rescaled range is able to distinguish between what we have termed "short-range" and "long-range" dependence; the classical rescaled range cannot. Whereas an extreme value for $Q_{n}$ indicates the likelihood of long-term memory, a rejection based on the $\tilde{Q}_{n}$ statistic is also consistent with short-range dependence or heterogeneity in the data. Of course, it is always possible to tabulate the limiting distribution of the classical $\mathrm{R} / \mathrm{S}$ statistic under a specific model of shortrange dependence; this obviously suffers from the drawback of specificity. The modified rescaled range converges weakly to the range of a Brownian bridge under general forms

${ }^{20}$ Although he does not suggest normalizing by $\partial_{n}$, Mandelbrot $(1972, p$. 285) was certainly aware of this problem. 
of weak dependence.

\section{R/S Analysis for Stock Market Returns.}

Greene and Fielitz (1977) were perhaps the first to apply R/S analysis to common stock returns. ${ }^{30}$ Their empirical analysis differs from ours in several respects. First, like Mandelbrot and Wallis (1969a), Greene and Fielitz compute R/S statistics but do not provide any sampling theory with which to judge their significance. Second, they use the $\tilde{Q}_{n}$ statistic which is not robust to short-range dependence. Third, they do not focus on the $\mathrm{R} / \mathrm{S}$ statistic itself, but rather on the behavior of its logarithm as the number of observations is increased. Although they use regression analysis to study this relation, they do not specify the properties of their regression equation, nor do they perform any diagnostics to check its specification. ${ }^{31}$ Finally, their data set covers a shorter time span [1963-1968], and they consider individual stock returns; we analyze aggregate stock returns indexes over a much longer time period.

To test for long-term memory in stock returns we use data from the Center for Research in Security Prices (CRSP) monthly and daily returns files, and the annual Standard and Poor's Composite Index data of Campbell and Shiller (1988). Tests are performed for the value- and equal-weighted CRSP indexes. Daily observations for the returns indexes are available from 3 July 1962 to 31 December 1987 yielding a sample size of 6,409 observations. Monthly indexes are each composed of 744 observations from 30 January 1926 to 31 December 1987. We also perform tests for weekly returns constructed from the daily returns file as in Lo and MacKinlay (1988), yielding 1,330 observations from 11 July 1962 to 30 December 1987. Finally, our annual data consists of 115 observations on the return to Standard and Poor's Composite Index spanning the period from 1872 to 1986 . The following statistic is computed for the various returns indexes:

$$
V_{n}(q) \equiv \frac{1}{\sqrt{n}} Q_{n} \stackrel{a}{\sim} V
$$

\footnotetext{
${ }^{80}$ More recent economic applications of $\mathrm{R} / \mathrm{S}$ analysis include Booth, Kaen and Koveos (1982), Helms, Kaen, and Rosenman (1981), and Kaen and Rosenman (1986).

${ }^{81}$ Davies and Harte (1987) show such tests to be significantly biased toward rejection even for a stationary AR(1) process with autoregressive parameter 0.3 .
} 
where the distribution $F_{V}$ of $V$ is given in (4.5). Using the values in Table 2a a test of the null hypothesis may be performed at the 95 percent level of confidence by accepting or rejecting according to whether $V_{n}$ is or is not contained in the interval $[0.809,1.862]$. This interval assigns equal probability to each tail; symmetric confidence intervals about the mean $\sqrt{\frac{\pi}{2}}$ of $V$ are given in Table $2 \mathrm{~b}$.

We have written $V_{n}(q)$ as a function of $q$ to emphasize the dependence of the modified rescaled range on the truncation lag. To check the sensitivity of the statistic to the lag length, we calculate $V_{n}(q)$ for several different values of q. The normalized classical Hurst-Mandelbrot rescaled range $\tilde{V}_{n}$ is also computed for comparison, where:

$$
\tilde{V}_{n} \equiv \frac{1}{\sqrt{n}} \tilde{Q}_{n} \stackrel{a}{\sim} \xi V
$$

Table 3 reports results for the daily equal- and value-weighted returns indexes. Panel A presents the $V_{n}(q)$ and $\tilde{V}_{n}$ statistics for the equal-weighted index for the entire sample period [the first row], two equally-partitioned sub-samples [the next two rows], and four equally-partitioned sub-samples [the next four rows]. The modified rescaled range is computed with $q$-values of $90,180,270$, and 360 days. The columns labelled "\%-Bias" report the estimated bias of the original rescaled range $\tilde{V}_{n}$, and is $100 \cdot(\hat{\xi}-1)$ where $\hat{\xi}=\hat{\sigma}_{n}(q) / s_{n}=\tilde{V}_{n} / V_{n}$.

Although Table 3 shows that the classical R/S statistic $\tilde{V}_{n}$ is statistically significant at the 5 percent level for the daily equal-weighted CRSP returns index, the modified $\mathrm{R} / \mathrm{S}$ statistic $V_{n}$ is not. While $\tilde{V}_{n}$ is 2.63 for the entire sample period the modified $\mathrm{R} / \mathrm{S}$ statistic is 1.46 with a truncation lag of 90 days, and 1.50 with a truncation lag of 360 days. The importance of normalizing by $\hat{\sigma}_{n}(q)$ is clear: dividing by $s_{n}$ imparts an upward bias of 80 percent!

The statistical insignificance of the modified $\mathrm{R} / \mathrm{S}$ statistics indicates that the data are consistent with the short-memory null hypothesis. The stability of the $V_{n}(q)$ across truncation lags $q$ also supports the hypothesis that there is little dependence in daily stock returns beyond one or two months. For example, using 90 lags yields a $V_{n}$ of 1.46 whereas 270 and 360 lags both yield 1.50, virtually the same point estimate. The results are robust to the sample period; none of the sub-period $V_{n}(q)$ 's are significant. The classical rescaled range is significant only in the first half of the sample for the value-weighted index [Panel $B]$, and is insignificant when the entire sample is used. 
Tables 4 and 5 report similar results for weekly and monthly returns indexes. For weekly returns, the four values of $q$ employed are 13, 26, 39, 52 weeks, and for monthly returns, we set $q$ to $3,6,9$, and 12 months. None of the modified R/S statistics are statistically significant at the 5 percent level in any sample period or sub-period for either indexes. The percentage bias is generally lower for weekly and monthly data, although it still ranges from -30.0 to 47.5 percent for weekly returns, and from -0.2 to 25.3 percent for monthly returns.

To develop further intuition for these results, Figure 2 contains the autocorrelograms of the daily, weekly, and monthly equal-weighted returns indexes, where the maximum lag is 360 for daily returns, 52 for weekly, and 12 for monthly. For all three indexes only the lowest order autocorrelation coefficients are statistically significant. For comparison, alongside each of the index's autocorrelogram is the autocorrelogram of the fractionally-differenced process (2.1) with $d=.25$ and the variance of the disturbance chosen to yield a first-order autocorrelation of $\frac{1}{3}$. Although the general shapes of the fractionally-differenced autocorrelograms seem consistent with the data, closer inspection reveals that the index autocorrelations decay much more rapidly. Therefore, although short-term correlations are large enough drive $\tilde{Q}_{n}$ and $Q_{n}$ apart, there is little evidence of long-range dependence in $Q_{n}$ itself.

Table 6 reports estimates of the rescaled range for annual stock returns data from 1872 to 1986, using Standard and Poor's Composite Index series of Campbell and Shiller (1988), adjusted for dividends. ${ }^{32}$ Even with a much longer time span, neither the classical nor the modified $\mathrm{R} / \mathrm{S}$ statistics are statistically significant.

The evidence in Tables 3 to 6 shows that the null hypothesis of short-range dependence cannot be rejected by the data; there is little support for long-term memory in stock returns. With adjustments for autocorrelation at lags up to one calendar year, estimates of the modified rescaled range are consistent with the null hypothesis of weak dependence. This reinforces Kandel and Stambaugh's (1988) contention that the longrun predictability of stock returns uncovered by Fama and French (1988) and Poterba and Summers (1988) may not be "long-run" in the time series sense, but may be the result of more conventional models of short-range dependence. Of course, since our inferences rely solely on asymptotic theory, the finite-sample size and power of our test must be explored before reaching further conclusions. We turn to these issues next.

82 I am grateful to John Campbell and Robert Shiller for sharing their data. 


\section{Size and Power.}

The fact that we have not rejected the null hypothesis of short-range dependence need not imply the absence of long-range dependence, but may merely be a symptom of low power. To explore this possibility, and to check the quality of our asymptotic approximations for various sample sizes, we perform several illustrative Monte Carlo experiments. Section 6.1 reports the empirical size of the test statistic under two Gaussian null hypotheses: i.i.d. and AR(1) disturbances. Section 6.2 presents power results against the fractionally-differenced process $(2.1)$ for $d=\frac{1}{3}$ and $-\frac{1}{3}$.

\subsection{The Size of the R/S Test.}

Table 7 a contains simulation results for the modified $\mathrm{R} / \mathrm{S}$ statistic with sample sizes of $100,250,500,750$, and 1000 under the null hypothesis of independently and identically distributed Gaussian errors. ${ }^{33}$ For each sample size the statistic $V_{n}(q)$ is computed with $q=0,5,10,25,50$; when $q=0, V_{n}(q)$ is identical to Mandelbrot's classical R/S statistic $\tilde{V}_{n}$. The entries in the last three columns show that the classical $\mathrm{R} / \mathrm{S}$ statistic tends to reject too frequently; even for sample sizes of 1000 the empirical size of a 5 percent test based on $\tilde{V}_{n}$ is 6.3 percent. The modified R/S statistic tends to be conservative for values of $q$ that are not too large relative to the sample size. For example, with 100 observations and 5 lags the empirical size of the 5 percent test using $V_{n}(q)$ is 2.1 percent. However, with 50 lags this test has a rejection rate of 31 percent! That the sampling properties worsen with the number of lags is not surprising; the imprecision with which the higher-order autocovariances are estimated can introduce considerable noise into the statistic. ${ }^{34}$

Table $7 \mathrm{~b}$ reports the results of simulations under the null hypothesis of a Gaussian AR(1) with autoregressive coefficient 0.5 ; recall that such a process is weakly dependent. The last three columns confirm the example of Section 3 and accord well with the results of Davies and Harte (1987): tests based on the classical R/S statistic have considerable power against an $\mathrm{AR}(1)$ null. In samples of only 100 observations the empirical size of the 5 percent test based on $\tilde{V}_{n}$ is 38 percent and increases to 61 percent for sample sizes of 1000 . In contrast, the empirical sizes of tests based on $V_{n}(q)$ are much closer

\footnotetext{
${ }^{33}$ All simulations were performed on a VAX 8700 in double precision using the random generator DRNNOA from IMSL Version 10.0 .

34 See Lo and MacKinlay (1989) for simulation evidence to this effect.
} 
to their nominal values since the short-range correlations are taken into account by the denominator $\hat{\sigma}_{n}(q)$ of $V_{n}(q)$.

\subsection{Power Against Fractionally-Differenced Alternatives.}

Tables $8 \mathrm{a}$ and $8 \mathrm{~b}$ report the power of the $\mathrm{R} / \mathrm{S}$ tests against the Gaussian fractionallydifferenced alternative:

$$
(1-L)^{d} \epsilon_{t}=\eta_{t} \quad, \quad \eta_{t} \text { i.i.d. } \mathrm{N}\left(0, \sigma_{\eta}^{2}\right)
$$

with $d=\frac{1}{3}$ and $-\frac{1}{3}$, and $\sigma_{\eta}^{2}$ chosen to yield a unit variance for $\epsilon_{t} .{ }^{35}$ For sample sizes of 100 tests based on $V_{n}(q)$ have very little power, but when the sample size reaches 250 the power increases dramatically. According to Table 8a, the power of the 5 percent test with $q=5$ against the $d=\frac{1}{3}$ alternative is 34.3 percent with 250 observations, 63.2 percent with 500 observations, and 83.6 percent with 1000 observations. For a given sample size, the power of the $V_{n}(q)$-based test declines as the number of lags is increased. This is due to the denominator $\hat{\sigma}_{n}(q)$, which generally increases with $q$ since there is positive dependence when $d=\frac{1}{3}$. The increase in the denominator decreases the variability of the statistic, pulling probability mass from both tails of the distribution towards the mean, and decreases the mean thereby reducing the frequency of draws in the right tail's critical region [where virtually all the power is coming from].

Against the $d=-\frac{1}{3}$ alternative, Table $8 \mathrm{~b}$ shows that the test seems to have somewhat higher power. However, in contrast to Table $8 \mathrm{a}$ the rejections are now coming from the left tail of the distribution, not the right. Moreover, for the larger sample sizes the power declines as the number of lags increases. Again this is due to the denominator $\hat{\sigma}_{n}(q)$, which declines as $q$ increases because the [theoretical] autocorrelations are all negative when $d=-\frac{1}{3}$. The resulting increase in the mean of $V_{n}(q)$ 's sampling distribution overwhelms the increase in its variability, leading to a lower rejection rate from the left tail.

Finally, Tables $9 \mathrm{a}$ and $\mathrm{b}$ report the results of simulations of $Q_{n}$ under the two nulls and two alternatives, where the truncation lag $q$ is chosen according to Andrews' (1988) data-dependent formula:

\footnotetext{
${ }^{85}$ In particular, $\sigma_{\eta}^{2}=\Gamma^{2}(1-d) / \Gamma(1-2 d)$.
} 


$$
q=\left[k_{n}\right] \quad, \quad s_{n} \equiv\left(\frac{2 n}{3}\right)^{\frac{1}{3}} \cdot\left(\frac{\hat{\rho}}{1-\hat{\rho}^{2}}\right)^{\frac{2}{3}}
$$

where $\left[k_{n}\right]$ denotes the greatest integer less than or equal to $k_{n}$ and $\hat{\rho}$ is the estimated first-order autocorrelation coefficient of the data. Also, in place of the Newey and West (1987) weights (4.3), Andrews (1988) suggests the alternative:

$$
\omega_{j}=1-\left|\frac{j}{k_{n}}\right| \text {. }
$$

Using this automatic procedure for selecting $q$, both the size and power of the test are comparable to the best cases in Tables 7 and 8 . This being the case, perhaps the datadependent method for selection the truncation lag is to be preferred since it eliminates one more degree of arbitrariness in our inferential procedure.

In summary, Tables 8 and 9 show that the modified R/S statistic has power against at least two specific models of long-term memory. Of course, the simulations are merely illustrative; a more conclusive study must examine the finite-sample size and power of the test for several other values of the differencing parameter $d$. Since our empirical work has employed data sampled at different frequencies [implying different values of $d$ for different sample sizes], the trade-off between the time span of the data and the frequency of observation for the test's power is an important issue. Nevertheless, the simulation results suggest that short-range dependence may be the more significant feature of stock market returns. 


\section{Conclusion.}

Our empirical results suggest that stock market returns do not exhibit long-range dependence. If the source of serial correlation is lagged adjustment to new information, the absence of strong dependence in stock returns should not be surprising from an economic standpoint given the frequency with which financial asset markets clear. Surely financial security prices must be immune to persistent informational asymmetries, especially over longer time spans. Perhaps the fluctuations of aggregate economic output are more likely to display such long run tendencies as Kondratiev and Kuznets have suggested, and this long-memory in output may eventually manifest itself in the return to equity. But if some form of long-run dependence is indeed present in stock returns, it will not be easily detected by any of our current statistical tools, especially in view of the optimality of the R/S statistic in the Mandelbrot and Wallis (1969) sense. Direct estimation of particular parametric models may provide more positive evidence of long-term memory and is currently being pursued by several investigators. ${ }^{36}$

\footnotetext{
${ }^{36}$ See, for example, Diebold and Rudebusch (1988), Fox and Taqqu (1986), Geweke and Porter-Hudak (1983), Sowell $(1987 \mathrm{a}, \mathrm{b})$, and Yajima $(1985,1988)$.
} 


\section{Appendix}

\section{Proof of Theorem 4.1:}

Let $S_{n}=\sum_{j=1}^{n} \epsilon_{j}$ and define the following function $Y_{n}(\tau)$ on $D[0,1]$ :

$$
Y_{n}(\tau)=\frac{1}{\hat{\sigma}_{n}(q) \sqrt{n}} S_{[n \tau]} \quad \tau \in[0,1]
$$

where $[n \tau]$ denotes the greatest integer less than or equal to $n \tau$. By convention, we set $Y_{n}(0) \equiv 0$. Under conditions $(A 1),\left(A 2^{\prime}\right),(A 3)-(A 5)$ Herrndorf $(1984)$ has shown that $Y_{n}(\tau) \Rightarrow W(\tau)$. But consider:

$$
\begin{aligned}
\operatorname{Max}_{1 \leq k \leq n} \frac{1}{\hat{\sigma}_{n}(q) \sqrt{n}} \sum_{j=1}^{k}\left(X_{j}-\bar{X}_{n}\right) & =\operatorname{Max}_{1 \leq k \leq n} \frac{1}{\hat{\sigma}_{n}(q) \sqrt{n}}\left(S_{k}-\frac{k}{n} S_{n}\right) \\
& =\operatorname{Max}_{0 \leq \tau \leq 1} Z_{n}(\tau)
\end{aligned}
$$

where:

$$
Z_{n}(\tau) \equiv Y_{n}(\tau)-\frac{[n \tau]}{n} Y_{n}(1)
$$

Since the sequence of functions $h_{n}$ that map $Y_{n}(\tau)$ to $Z_{n}(\tau)$ satisfy the conditions of Lemma 4.2, where the limiting mapping $h$ takes $Y_{n}(\tau)$ to $Y_{n}(\tau)-\tau Y_{n}(1)$, we conclude that:

$$
h_{n}\left(Y_{n}(\tau)\right)=Z_{n}(\tau) \Rightarrow h(W(\tau))=W(\tau)-\tau W(1)=W^{\circ}(\tau)
$$

The rest of the theorem follows directly from repeated application Lemma 4.2.

Q.E.D. 


\section{Proof of Theorem 4.2:}

From Billingsley (1968, p. 85$)$ we have: ${ }^{37}$

$$
P\left(m<m^{\circ} \leq M^{\circ}<M\right)=\sum_{k=-\infty}^{\infty} \mathrm{e}^{-2(k c)^{2}}-\sum_{k=-\infty}^{\infty} \mathrm{e}^{-2(M+k c)^{2}}
$$

where $c \equiv M-m>0$. It may be verified directly that $(A .4)$ is uniformly convergent in $m$ and $M$, hence the interchange of limits to follow is appropriate. Since $P\left(M^{\circ}<\right.$ $M)=1-e^{-2 M^{2}}[$ let $m \rightarrow-\infty$ in $(A .4)]$ and $P\left(m<m^{\circ} \leq M^{\circ}<M\right)+\mathrm{P}\left(m^{\circ}<\right.$ $\left.m, M^{\circ}<M\right)=P\left(M^{\circ}<M\right)$, we have:

$$
P\left(m^{\circ}<m, M^{\circ}<M\right)=\sum_{k \neq 0}\left\{e^{-2(M+k c)^{2}}-e^{-2(k c)^{2}}\right\}
$$

The joint density $f(m, M)$ of $\left(m^{\circ}, M^{\circ}\right)$ is obtained by differentiating $(A .4)$ with respect to $m$ and $M$ [note the sign change]:

$$
\begin{aligned}
f(m, M) & =-\frac{\partial^{2}}{\partial m \partial M} P\left(m<m^{\circ} \leq M^{\circ}<M\right) \\
& =4 \sqrt{2 \pi} \sum_{k=-\infty}^{\infty}\left\{k(k+1)\left[1-\alpha_{k}^{2}\right] \phi\left(\alpha_{k}\right)-k^{2}\left[1-\beta_{k}^{2}\right] \phi\left(\beta_{k}\right)\right\}(A
\end{aligned}
$$

where $\alpha_{k} \equiv 2[M(k+1)-m k], \beta_{k} \equiv 2 k(M-m)$, and $\phi(x)$ is the standard Gaussian density function $\frac{1}{\sqrt{2 \pi}} e^{-\frac{x^{2}}{2}}$. Since $(A .6 b)$ is also uniformly convergent in $(m, M)$, this is indeed the joint density function of $\left(m^{\circ}, M^{\circ}\right)$. Let $V \equiv M^{\circ}-m^{\circ}$. We seek the probability $P(V<v)$, which is simply:

$$
P(V<v)=\int_{-v}^{0} \int_{0}^{m+v} f(m, M) d M d m
$$

${ }^{37}$ See also Darling and Erdös (1956) and Feller (1951). 


$$
\begin{array}{r}
=4 \sqrt{2 \pi} \sum_{k=-\infty}^{\infty}\left\{k(k+1) \iint_{U}\left[1-\alpha_{k}^{2}\right] \phi\left(\alpha_{k}\right) d M d m-\right. \\
\left.k^{2} \iint_{U}\left[1-\beta_{k}^{2}\right] \phi\left(\beta_{k}\right) d M d m\right\}
\end{array}
$$

where $U$ denotes the region of integration in $(\mathrm{A.7a})$ and the uniform convergence of $(A .6 b)$ allows us to integrate termwise. Using the fact that $\int x \phi(x) d x=-\phi(x)$ and $\int\left(1-x^{2}\right) \phi(x) d x=x \phi(x)$ then yields the following:

$\iint_{U}\left[1-\alpha_{k}^{2}\right] \phi\left(\alpha_{k}\right) d M d m=\frac{1}{2(k+1)}\left\{\frac{2(k+1)}{4 k} \phi(2 k v)-\frac{1}{2} \phi(2[k+1] v)-\frac{1}{2 k} \phi(0)\right\}$

$\iint_{U}\left[1-\beta_{k}^{2}\right] \phi\left(\beta_{k}\right) d M d m=\frac{1}{4 k^{2}}\left\{\left[(2 k v)^{2}+1\right] \phi(2 k v)-\phi(0)\right\}$

Substituting these expressions into $(A .7 b)$ and simplifying then yields:

$$
\begin{gathered}
P(V<v)=\sum_{k=-\infty}^{\infty}\left\{k\left(1-4 k v^{2}\right) \mathrm{e}^{-2(k v)^{2}}-k \mathrm{e}^{-2([k+1] v)^{2}}\right\} \\
=\sum_{k=-\infty}^{\infty} k \mathrm{e}^{-2(k v)^{2}}-4 \sum_{k=-\infty}^{\infty} k^{2} v^{2} \mathrm{e}^{-2(k v)^{2}}- \\
\sum_{k=-\infty}^{\infty} k \mathrm{e}^{-2([k+1] v)^{2}}
\end{gathered}
$$

By symmetry the first summation in $(A .8 b)$ is zero and the index of the second summation may be taken from 1 to infinity if the summands are doubled. Further cancellations in the third summation of $(A .8 b)$ then yield the desired result:

$$
P(V<v)=1+2 \sum_{k=1}^{\infty}\left(k-4 k^{2} v^{2}\right) e^{-2(k v)^{2}}
$$


The density function follows by differentiating the uniformly convergent series ( $A .9$ ) termwise and verifying that the resulting series also converges uniformly.

Q.E.D. 


\section{References}

Andrews, D., 1984, "Non-Strong Mixing Autoregressive Processes," Journal of Applied Probability 21, 930-934.

- 1988, "Heteroskedasticity and Autocorrelation Consistent Covariance Matrix Estimation," Cowles Foundation Discussion Paper No. 877, Yale University.

Billingsley, P., 1968, Convergence of Probability Measures. New York: John Wiley and Sons.

Booth, G., Kaen, F. and P. Koveos, 1982, "R/S Analysis of Foreign Exchange Rates Under Two International Monetary Regimes," Journal of Monetary Economics 10, 407-415.

Campbell, J. and G. Mankiw, 1987, "Are Output Fluctuations Transitory?," Quarterly Journal of Economics 102, 857-880.

—, and R. Shiller, 1988, "Stock Prices, Earnings and Expected Dividends," forthcoming in Journal of Finance.

Darling, D. and P. Erdös, 1956, "A Limit Theorem for the Maximum of Normalized Sums of Independent Random Variables," Duke Mathematical Journal 23, 143-155.

Davies, R. and D. Harte, 1987, "Tests for Hurst Effect," Biometrika 74, 95-101.

DeBondt, W. and R. Thaler, 1985, "Does the Stock Market Overreact?" Journal of Finance 40, 793-805.

Diebold, F. and G. Rudebusch, 1988, "Long Memory and Persistence in Aggregate Output," Federal Reserve Board Discussion Paper No. 7, Washington D.C.

Eberlein, E. and M. Taqqu, 1986, Dependence in Probability and Statistics. Progress in Probability and Statistics 11. Birkhäuser: Boston.

Fama, E. and K. French, 1988, "Permanent and Temporary Components of Stock Prices," Journal of Political Economy 96, 246-273.

Feller, W., 1951, "The Asymptotic Distribution of the Range of Sums of Independent Random Variables," Annals of Mathematical Statistics 22, 427-432.

Fox, R. and M. Taqqu, 1986, "Large-Sample Properties of Parameter Estimates for Strongly Dependent Stationary Gaussian Time Series," Annals of Statistics 14, 517-532.

Geweke, J. and S. Porter-Hudak, 1983, "The Estimation and Application of Long Memory Time Series Models," Journal of Time Series Analysis 4, 221-238.

Granger, C., 1980, "Long Memory Relationships and the Aggregation of Dynamic Models," Journal of Econometrics 14, 227-238.

, and R. Joyeux, 1980, "An Introduction to Long-Memory Time Series Models and Fractional Differencing," Journal of Time Series Analysis 1, 15-29. 
Greene, M. and B. Fielitz, 1977, "Long-Term Dependence in Common Stock Returns," Journal of Financial Economics 4, 339-349.

Hall, P. and C. Heyde, 1980, Martingale Limit Theory and Its Application, New York: Academic Press.

Hannan, E., Multiple Time Series, New York: John Wiley and Sons.

Hansen, L., 1982, "Large Sample Properties of Generalized Method of Moments Estimators," Econometrica 50, 1029-1054.

Haubrich, J. and A. Lo, 1989, "The Sources and Nature of Long-Term Dependence in the Business Cycle," NBER Working Paper No. 2951.

Helms, B., Kaen, F. and R. Rosenman, 1984, "Memory in Commodity Futures Contracts," Journal of Futures Markets 4, 559-567.

Herrndorf, N., 1984, "A Functional Central Limit Theorem for Weakly Dependent Sequences of Random Variables," Annals of Probability 12, 141-153.

Herrndorf, N., 1985, "A Functional Central Limit Theorem for Strongly Mixing Sequences of Random Variables," $Z$. Wahrscheinlichkeitstheorie verw. Gebiete, 541550 .

Hosking, J., 1981, "Fractional Differencing," Biometrika 68, 165-176.

Hurst, H., 1951, "Long Term Storage Capacity of Reservoirs," Transactions of the American Society of Civil Engineers 116, 770-799.

- 1956, "Methods of Using Long Term Storage in Reservoirs," Proceedings of the Institute of Civil Engineers 1, 519-543.

Jegadeesh, N., 1988, “Evidence of Predictable Behavior of Security Returns," Anderson Graduate School of Management Working Paper \#6-88, U.C.L.A.

— 1989, "On Testing for Slowly Decaying Components in Stock Prices," unpublished manuscript, Anderson Graduate School of Management, U.C.L.A.

Kaen, F. and R. Rosenman, 1986, "Predictable Behavior in Financial Markets: Some Evidence in Support of Heiner's Hypothesis," American Economic Review 76, 212 220.

Kandel, S. and R. Stambaugh, 1988, "Modelling Expected Stock Returns for Long and Short Horizons," Rodney L. White Center Working Paper No. 42-88, Wharton School, University of Pennsylvania.

Lo, A. and C. MacKinlay, 1988, "Stock Market Prices Do Not Follow Random Walks: Evidence from a Simple Specification Test," Review of Financial Studies 1, 41-66.

- 1989, "The Size and Power of the Variance Ratio Test in Finite Samples: A Monte Carlo Investigation," Journal of Econometrics 40, 203-238.

Mandelbrot, B., 1971, "When Can Price Be Arbitraged Efficiently? A Limit to the Validity of the Random Walk and Martingale Models," Review of Economics and Statistics 53, 225-236. 
1972, "Statistical Methodology for Non-Periodic Cycles: From the Covariance to R/S Analysis," Annals of Economic and Social Measurement 1, 259-290.

, 1975, "Limit Theorems on the Self-Normalized Range for Weakly and Strongly Dependent Processes," Z. Wahrscheinlichkeitstheorie verw. Gebiete 31, 271-285.

- and M. Taqqu, 1979, "Robust R/S Analysis of Long-Run Serial Correlation," Bulletin of the International Statistical Institute 48, Book 2, 59-104.

- and J. Van Ness, 1968, "Fractional Brownian Motion, Fractional Noises and Applications," S.I.A.M. Review 10, 422-437.

- and J. Wallis, 1968, "Noah, Joseph and Operational Hydrology," Water Resources Research 4, 909-918.

- 1969a, "Computer Experiments with Fractional Gaussian Noises. Parts 1, 2, 3," Water Resources Research 5, 228-267.

- 1969b, "Some Long Run Properties of Geophysical Records," Water Resources Research 5, 321-340.

- 1969c, "Robustness of the Rescaled Range R/S in the Measurement of Noncyclic Long Run Statistical Dependence," Water Resources Research 5, 967-988.

McLeish, D., 1977, “On the Invariance Principle for Nonstationary Mixingales,” Annals of Probability 5, 616-621.

Merton, R., 1987, "On the Current State of the Stock Market Rationality Hypothesis," in Macroeconomics and Finance: Essays in Honor of Franco Modigliani, R. Dornbusch, S. Fischer, and J. Bossons eds., M.I.T. Press.

Newey, W. and K. West, 1987, "A Simple Positive Definite, Heteroscedasticity and Autocorrelation Consistent Covariance Matrix," Econometrica 55, 703-705.

Phillips, P., 1987, “Time Series Regression with a Unit Root," Econometrica 55, 277301 .

Poterba, J. and L. Summers, 1988, "Mean Reversion in Stock Returns: Evidence and Implications," Journal of Financial Economics 22, 27-60.

Rippl, W., 1883, "The Capacity of Storage Reservoirs for Water Supply," Proceedings of the Institute of Civil Engineers 71, 270-278.

Rosenblatt, M., 1956, "A Central Limit Theorem and a Strong Mixing Condition," Proceedings of the National Academy of Sciences 42, 43-47.

Sowell, F., 1987a, "Fractional Unit Root Distributions," Discussion Paper No: 87-05, Institute of Statistics and Decision Sciences, Duke University.

- $1987 \mathrm{~b}$, "Maximum Likelihood Estimation of Fractionally Integrated Time Series Models," working paper, Duke University.

White, H., 1980, "A Heteroscedasticity-Consistent Covariance Matrix Estimator and a Direct Test for Heteroscedasticity," Econometrica 48, 817-838. 

York.

1984, Asymptotic Theory for Econometricians. John Wiley and Sons, New and I. Domowitz, 1984, "Nonlinear Regression with Dependent Observations," Econometrica 52, 143-162.

Wooldridge, J. and H. White, "Some Invariance Principles and Central Limit Theorems for Dependent Heterogenous Processes," Econometric Theory 4, 210-230.

Yajima, Y., 1985, “On Estimation of Long-Memory Time Series Models," Australian Journal of Statistics, 303-320.

1988, "On Estimation of a Regression Model with Long-Memory Stationary Errors," Annals of Statistics 16, 791-807. 


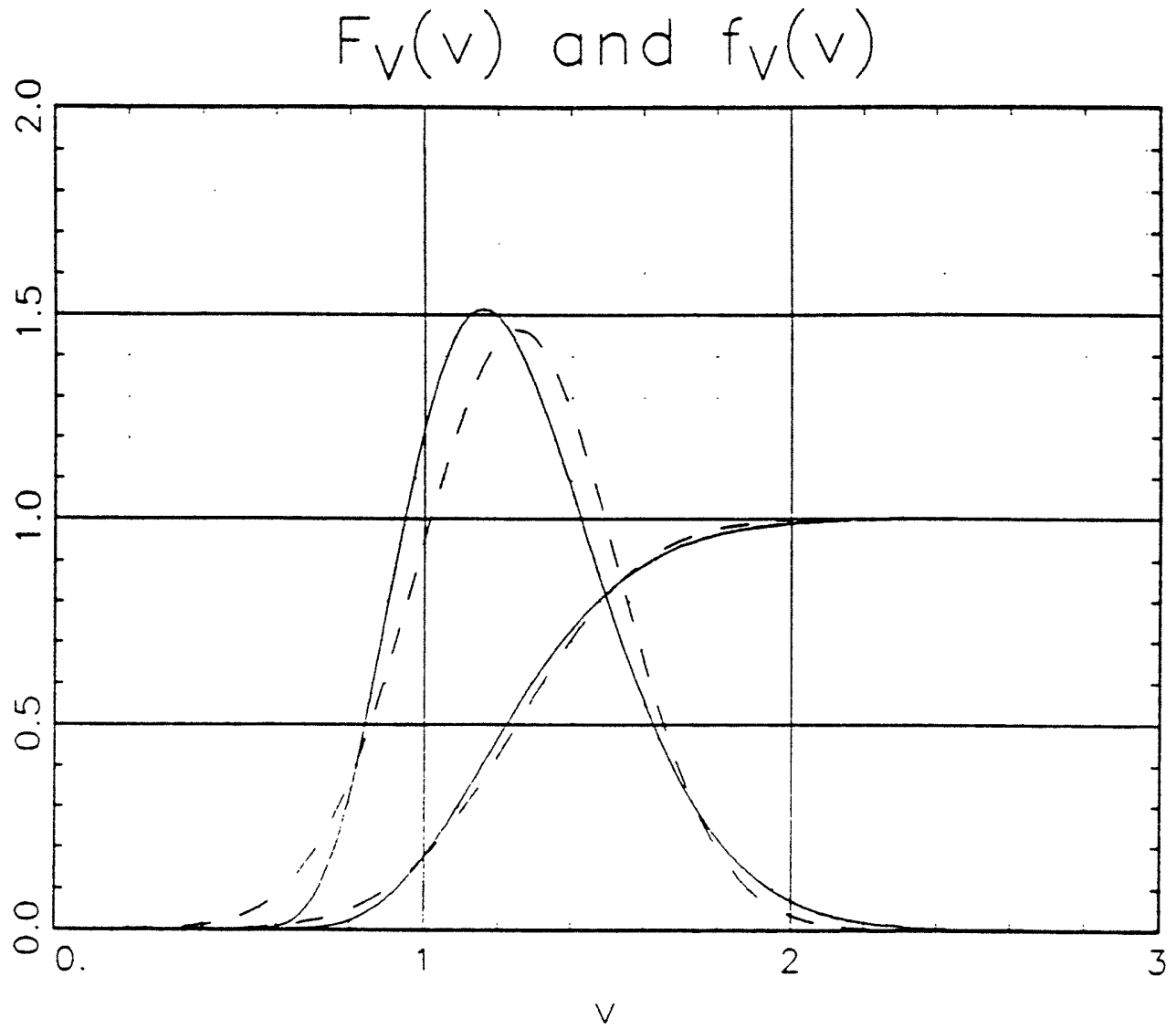

Figure 1.

Distribution and density function of the range $V$ of a Brownian bridge. Dashed curves are the normal distribution and density functions with mean and variance equal to those of $V$. 

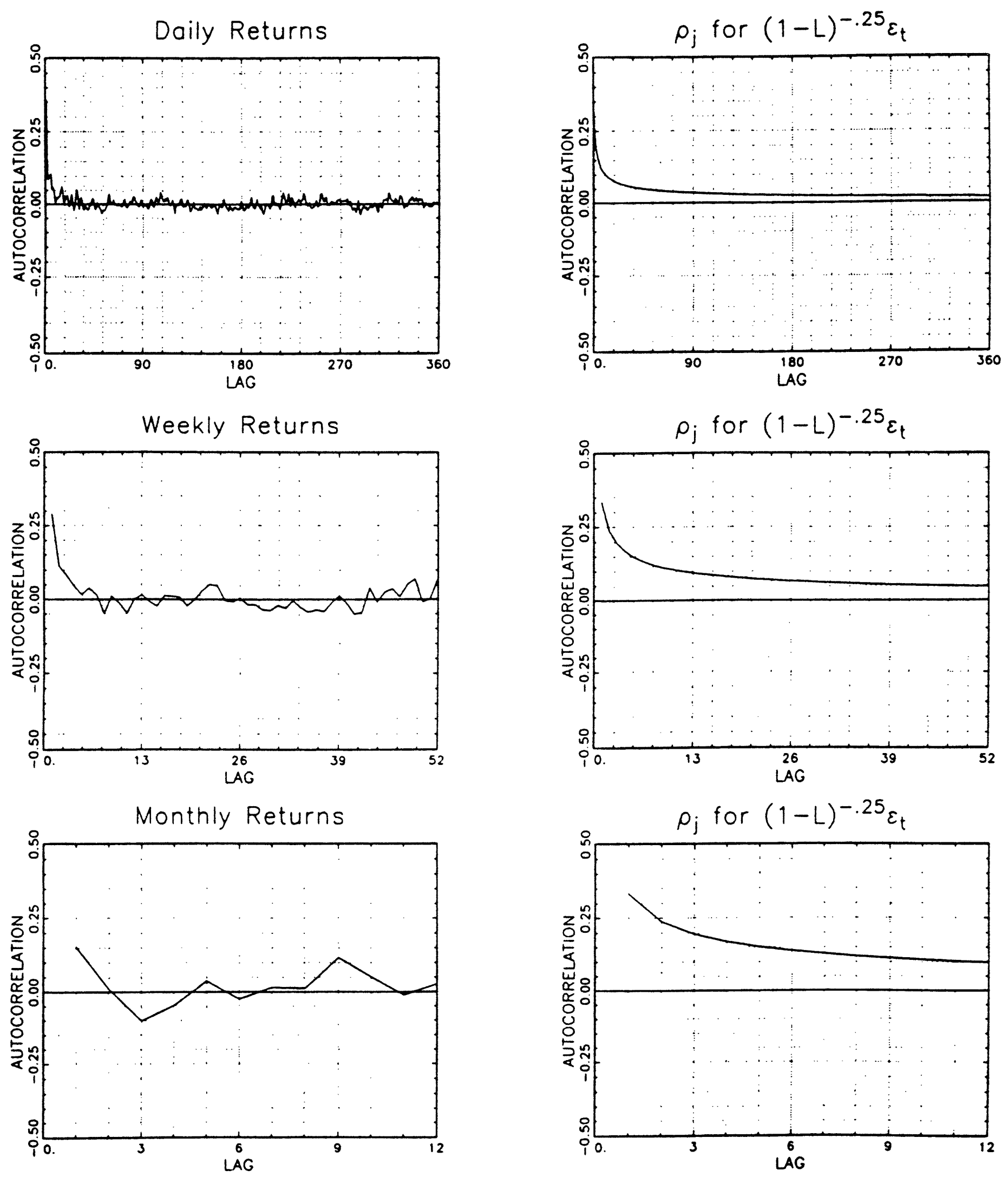

Figure 2.

Autocorrelograms of equally-weighted CRSP stock returns indexes and fractionally-differenced process with $d=\frac{1}{4}$. The sample period for the daily and weekly returns indexes is July 1962 to December 1987; the monthly index spans the period from January 1926 to December 1987. 


\section{Table 1}

Comparison of autocorrelation functions of fractionally differenced time series $(1-L)^{d} X_{t}=$ $\epsilon_{t}$ for $d=\frac{1}{3},-\frac{1}{3}$, with that of an $A R(1) X_{t}=\rho X_{t-1}+\epsilon_{t}, \rho=.5$. The variance of $\epsilon_{t}$ was chosen to yield a unit variance for $X_{t}$ in all three cases.

\begin{tabular}{|c|c|c|c|}
\hline $\begin{array}{c}\text { Lag } \\
k\end{array}$ & $\begin{array}{c}\rho(k) \\
{\left[d=\frac{1}{3}\right]}\end{array}$ & $\begin{array}{c}\rho(k) \\
{\left[d=-\frac{1}{3}\right]}\end{array}$ & $\begin{array}{c}\rho(k) \\
{[A R(1), \rho=.5]}\end{array}$ \\
\hline \hline & & & \\
1 & 0.500 & -0.250 & 0.500 \\
2 & 0.400 & -0.071 & 0.250 \\
3 & 0.350 & -0.036 & 0.125 \\
4 & 0.318 & -0.022 & 0.063 \\
5 & 0.295 & -0.015 & 0.031 \\
10 & 0.235 & -0.005 & 0.001 \\
25 & 0.173 & -0.001 & 0.000 \\
50 & 0.137 & -0.000 & 0.000 \\
100 & 0.109 & -0.000 & 0.000 \\
& & & \\
\hline
\end{tabular}


Table 2a. Fractiles of the Distribution $F_{V}(v)$.

\begin{tabular}{|c|c|c|c|c|c|c|c|c|}
\hline$P(V<v)$ & .005 & .025 & .050 & .100 & .200 & .300 & .400 & .500 \\
\hline \hline$v$ & 0.721 & 0.809 & 0.861 & 0.927 & 1.018 & 1.090 & 1.157 & 1.223 \\
\hline
\end{tabular}

\begin{tabular}{|c|c|c|c|c|c|c|c|c|}
\hline$P(V<v)$ & .543 & .600 & .700 & .800 & .900 & .950 & .975 & .995 \\
\hline \hline$v$ & $\sqrt{\frac{\pi}{2}}$ & 1.294 & 1.374 & 1.473 & 1.620 & 1.747 & 1.862 & 2.098 \\
\hline
\end{tabular}

Table 2b. Symmetric Confidence Intervals About the Mean.

\begin{tabular}{|c|c|}
\hline$P\left(\sqrt{\frac{\pi}{2}}-\gamma<V<\sqrt{\frac{\pi}{2}}+\gamma\right)$ & $\gamma$ \\
\hline \hline .001 & 0.748 \\
.050 & 0.519 \\
.100 & 0.432 \\
.500 & 0.185 \\
\hline
\end{tabular}




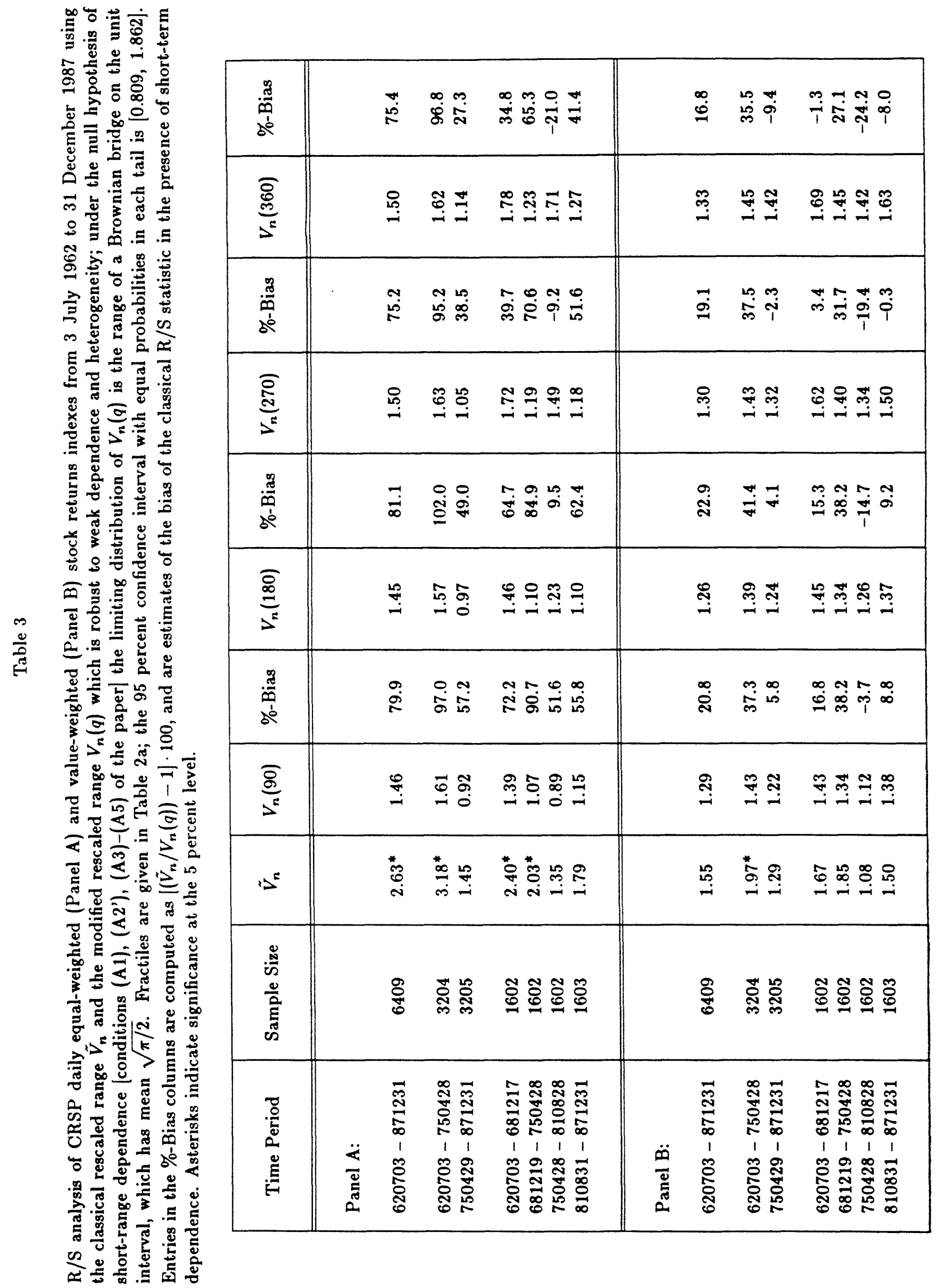




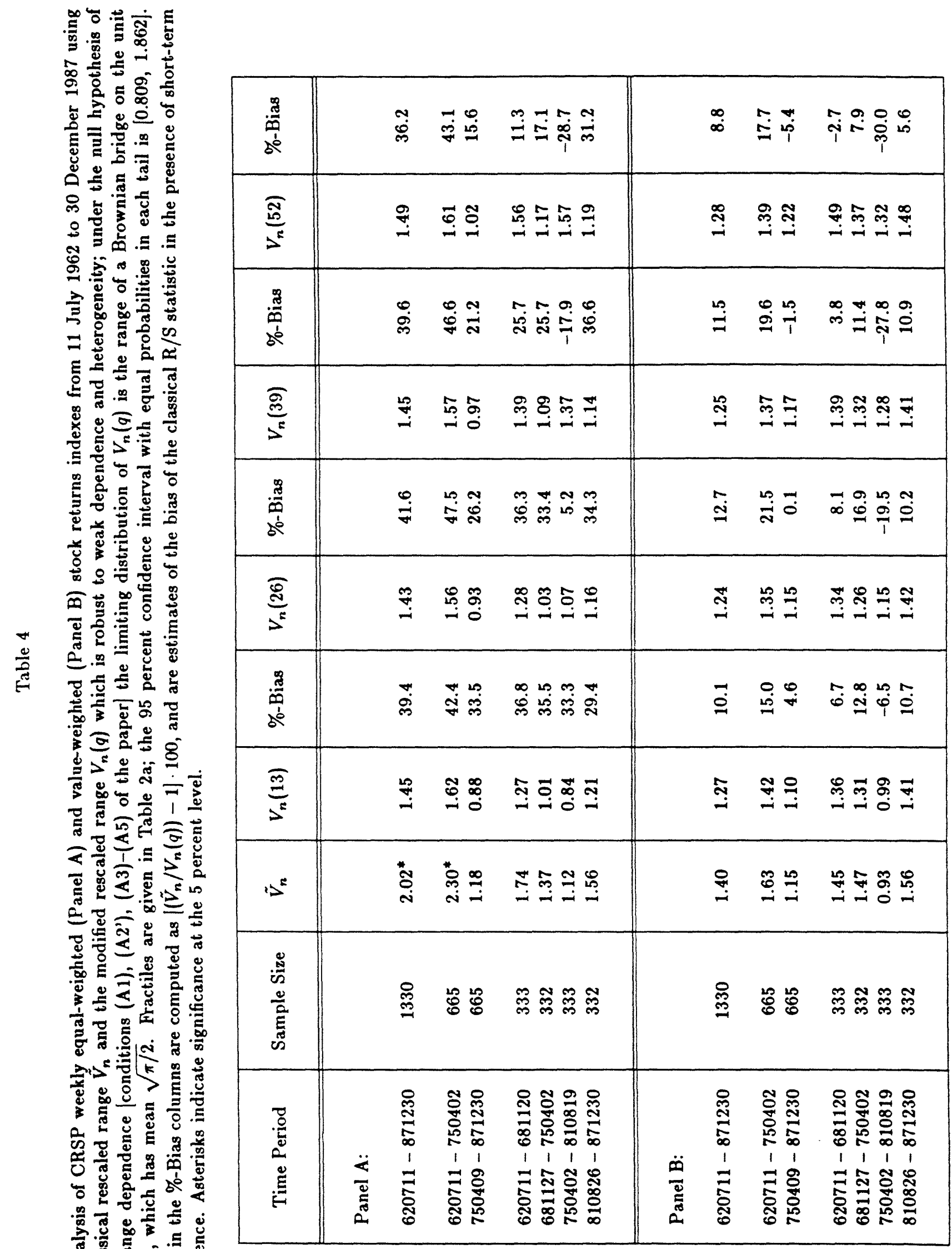




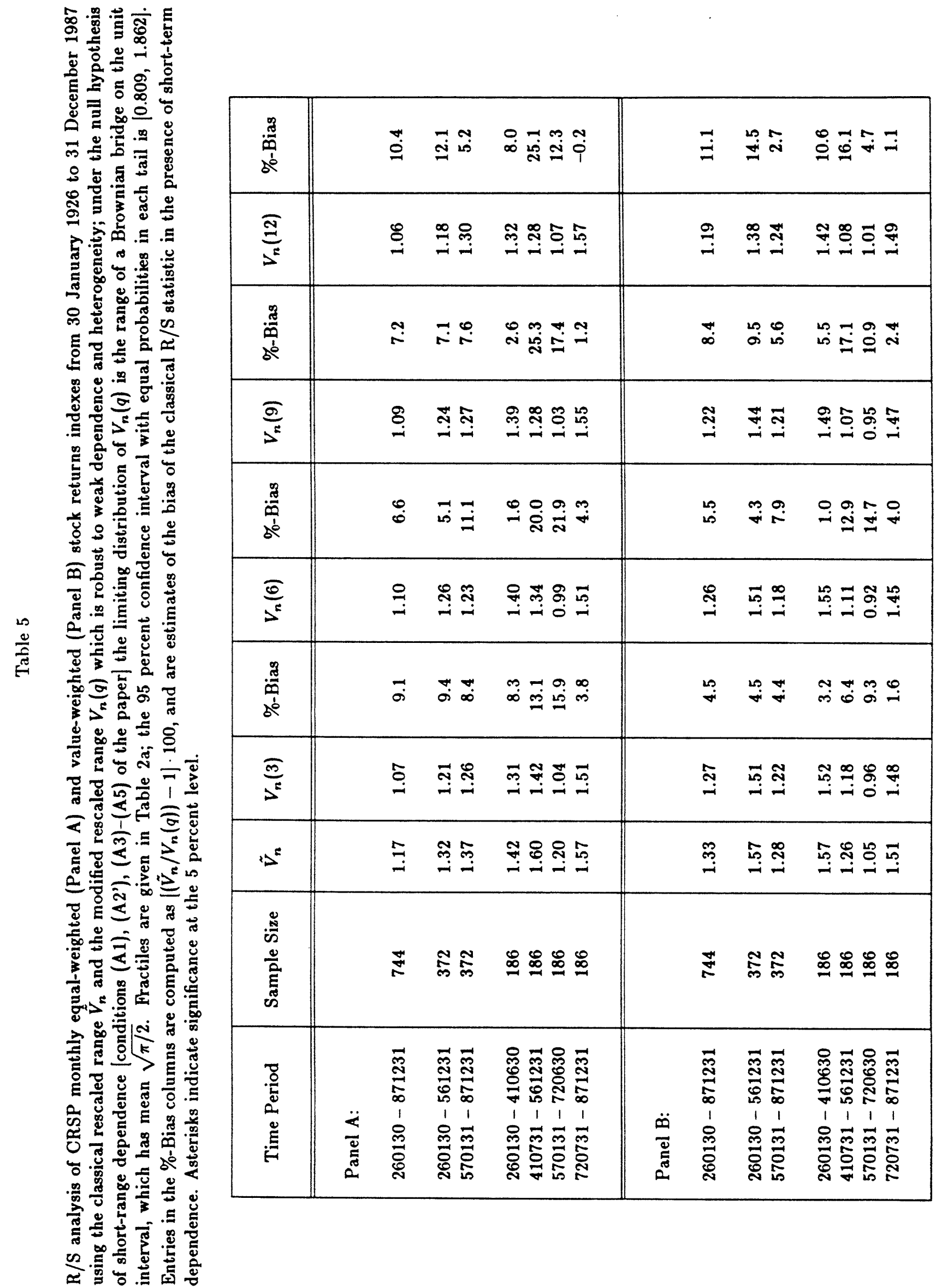


$\mathrm{R} / \mathrm{S}$ analysis of annual stock returns on Standard and Poor's Composite Index (including dividends) from 1872 to $1986,{ }^{1}$ using the classical rescaled range $\tilde{V}_{n}$ and the modified rescaled range $V_{n}(q)$ which is robust to weak dependence and heterogeneity; under the null hypothesis of short-range dependence [conditions (A1), (A2'), (A3)-(A5) of the paper] the limiting distribution of $V_{n}(q)$ is the range of a Brownian bridge, which has mean $\sqrt{\pi / 2}$. Fractiles are given in Table $2 \mathrm{a}$; the 95 percent confidence interval with equal probabilities in both tails is $[0.809,1.862]$. Entries in the \%-Bias columns are computed as $\left[\left(\tilde{V}_{n} / V_{n}\right)-1\right] \cdot 100$, and are estimates of the bias of the classical R/S statistic in the presence of short-term dependence. Asterisks indicate significance at the 5 percent level.

\begin{tabular}{|c|c|c|c|}
\hline$q$ & $\tilde{V}_{n}$ & $V_{n}(q)$ & \%-Bias \\
\hline \hline & & & \\
1 & 0.83 & 0.81 & 2.8 \\
2 & 0.83 & 0.87 & -4.2 \\
3 & 0.83 & 0.89 & -5.9 \\
4 & 0.83 & 0.92 & -9.4 \\
5 & 0.83 & 0.98 & -15.0 \\
\hline
\end{tabular}

\footnotetext{
${ }^{1}$ Since the S\&P Composite Index does not include dividends, the total dividends series (per share for the year, adjusted to the index) was added to the returns series. I am grateful to John Campbell and Robert Shiller for sharing this data set, more fully described in Campbell and Shiller (1988).
} 


\begin{tabular}{|c|c|c|c|c|c|c|c|c|c|c|c|}
\hline 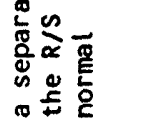 & $\stackrel{0}{\stackrel{W}{W}}$ & $\stackrel{m}{\frac{m}{0}}$ & 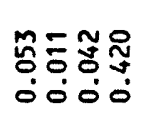 & $\frac{a}{0}$ & 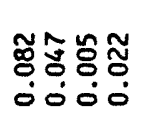 & $\frac{\bar{N}}{0}$ & 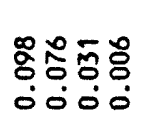 & $\stackrel{0}{\square}$ & 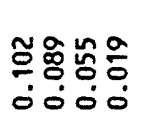 & $\stackrel{0}{\frac{0}{0}}$ & 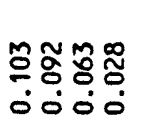 \\
\hline 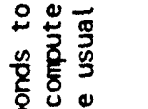 & 㤐 & $\begin{array}{l}\stackrel{a}{0} \\
\dot{0}\end{array}$ & 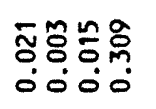 & $\begin{array}{l}\tilde{\hat{O}} \\
\dot{0} \\
0\end{array}$ & 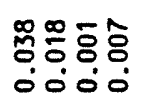 & 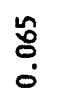 & 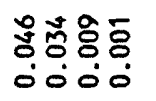 & $\begin{array}{l}\$ \\
0 \\
0\end{array}$ & 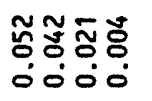 & Oै. & 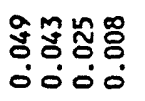 \\
\hline 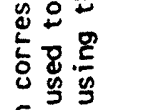 & 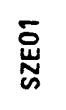 & $\begin{array}{l}\bar{m} \\
\dot{0}\end{array}$ & 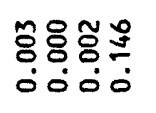 & $\begin{array}{l}\infty \\
0 \\
0\end{array}$ & 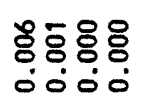 & $\stackrel{5}{0}$ & 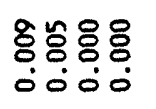 & $\begin{array}{l}0 \\
0 \\
0\end{array}$ & 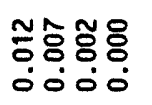 & 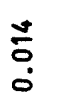 & 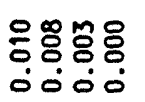 \\
\hline 舟 & $\begin{array}{l}\tilde{\alpha} \\
\alpha \\
\alpha\end{array}$ & $\begin{array}{l}\stackrel{\infty}{8} \\
0 \\
0\end{array}$ & 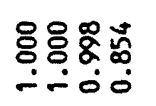 & $\begin{array}{l}\infty \\
\& \\
0\end{array}$ & ర్రిర్రిర్రి & के & 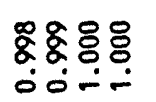 & $\begin{array}{l}\stackrel{\circ}{2} \\
0 \\
0\end{array}$ & 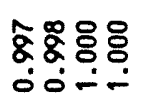 & $\underset{8}{2}$ & 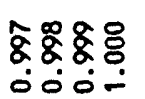 \\
\hline क्ष & $\underset{\alpha}{\kappa}$ & $\tilde{\xi}$ & 영ㅇㅇㅎㅀㅎㅜ & $\approx$ & 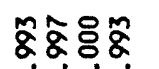 & జ & 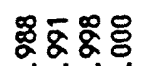 & $\bar{\Phi}$ & 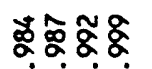 & مे & 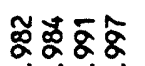 \\
\hline$\infty \Phi$ & & 0 & $0-00$ & 0 & $00-0$ & 0 & $000-$ & 0 & 0000 & 0 & 000 \\
\hline 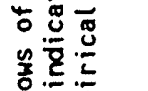 & 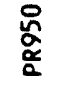 & $\begin{array}{l}a \\
a \\
a \\
0\end{array}$ & 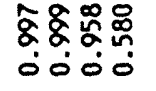 & $\begin{array}{l}a \\
\text { ò } \\
\text { o }\end{array}$ & 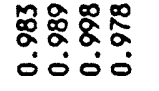 & $\begin{array}{l}\overline{0} \\
\vdots \\
0\end{array}$ & 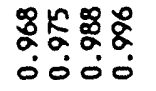 & 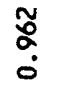 & 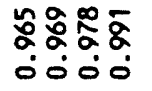 & $\begin{array}{l}8 \\
0 \\
0\end{array}$ & 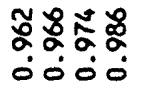 \\
\hline & \& & 䒘 & 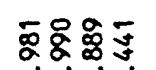 & $\stackrel{\infty}{\alpha}$ & 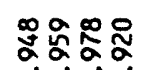 & $\approx$ & 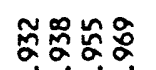 & $\frac{a}{a}$ & 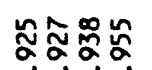 & $\frac{\infty}{a}$ & 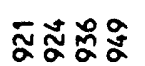 \\
\hline m & $\stackrel{\alpha}{a}$ & $\dot{0}$ & $\therefore 0^{\circ} 0^{\circ}$ & $\ddot{0}$ & $\circ 0^{\circ} \circ$ & $\dot{0}$ & 0000 & $\dot{0}$ & $\therefore 0^{\circ} \circ$ & $\dot{0}$ & $\because 000$ \\
\hline & $\frac{8}{\frac{0}{a}}$ & 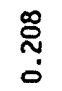 & 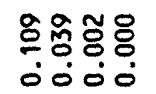 & $\frac{N}{0}$ & 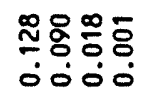 & $\frac{0}{0}$ & 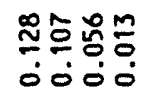 & $\frac{\bar{t}}{0}$ & 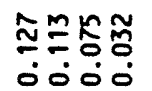 & $\frac{\infty}{\stackrel{m}{0}}$ & 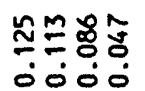 \\
\hline 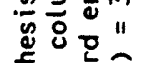 & 옹 & $\underline{m}$ & 앵응융용 & 8 & ผิ์ & ळ & ซิํㅎㄷㅇ응 & $\stackrel{\infty}{0}$ & 홍쏭쏭응 & $\kappa$ & 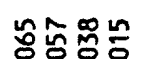 \\
\hline \pm & $\frac{\alpha}{\alpha}$ & $\dot{0}$ & 0000 & 0 & $0000^{\circ}$ & 0 & $00^{\circ} 0^{\circ}$ & 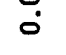 & $00^{\circ} 0^{\circ}$ & 0 & تهi \\
\hline 岕 & $\cong$ & $\overline{0}$ & 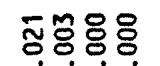 & జి & 퉁융ㅇㅇㅇㅇ & $\hat{\sigma}$ & 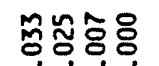 & $\tilde{\sigma}$ & 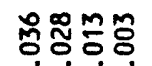 & $\tilde{\sigma}$ & ิํㅇํํㅇㅇㅇㅇ \\
\hline تُ & & 0 & 0000 & 0 & 0000 & 0 & 0000 & 0 & 0000 & 0 & 0000 \\
\hline & 嗏 & $\begin{array}{l}\text { Oे } \\
\dot{0}\end{array}$ & 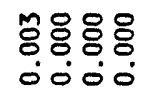 & $\stackrel{0}{0}$ & 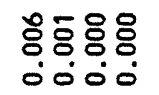 & $\begin{array}{l}\bar{\sigma} \\
0 \\
0\end{array}$ & 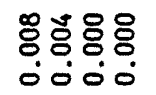 & $\begin{array}{l}\tilde{0} \\
0 \\
0\end{array}$ & 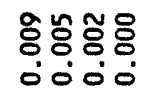 & $\begin{array}{l}0 \\
0 \\
0\end{array}$ & 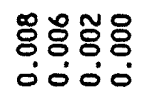 \\
\hline & $\frac{a}{\frac{a}{x}}$ & $\underset{0}{\tilde{S}}$ & $\begin{array}{l}\bar{\pi} \\
\tilde{m} \\
0.00 \\
0 \\
0\end{array}$ & 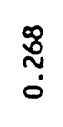 & 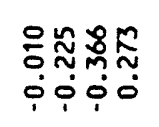 & $\begin{array}{l}0 \\
n \\
0\end{array}$ & 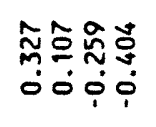 & 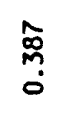 & 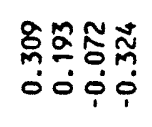 & $\underset{\tilde{3}}{\stackrel{\sim}{0}}$ & 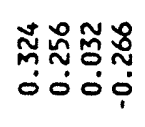 \\
\hline & 妥 & $\begin{array}{l}0 \\
0 \\
0\end{array}$ & 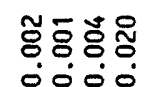 & 立 & 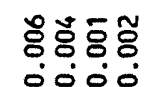 & $m_{0}^{m}$ & 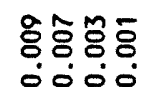 & $\tilde{a}$ & 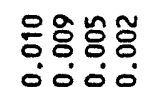 & $\stackrel{\sim}{0}$ & 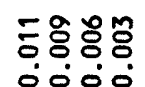 \\
\hline & $\therefore$ & $\stackrel{\infty}{\sim}$ & 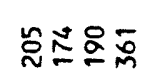 & $\hat{\sim}$ & $\bar{\sim} \frac{a}{\sim} \stackrel{5}{=}$ & $\bar{\Sigma}$ & œ & $\stackrel{N}{N}$ & 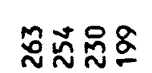 & $\underset{N}{N}$ & 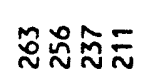 \\
\hline & & $0^{\circ}$ & & $\dot{0}$ & $\dot{0} \dot{0} \dot{0}$ & $\dot{0}$ & $\dot{0} \dot{0} \dot{0} \dot{0}$ & $\dot{0}$ & $\dot{000}$ & $\dot{0}$ & 0000 \\
\hline 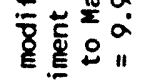 & 趇 & $\bar{\Xi}$ & 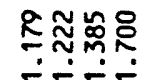 & $\stackrel{\varpi}{=}$ & 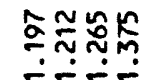 & ָัّ & 을 & 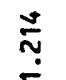 & กิ సุำ & $\stackrel{0}{\check{\underbrace{}}}$ & 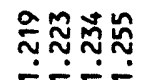 \\
\hline 䎡 & $\frac{z}{x}$ & ă & 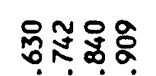 & $\underset{\sigma}{\infty}$ & 㱏䓟吕吕 & ڤึ & ะั้ำ & \&్ర & 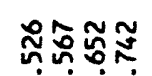 & ڤొ & 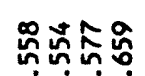 \\
\hline 管 & & 0 & $0^{\circ} 0^{\circ} 0^{\circ}$ & $\dot{0}$ & 000 & 0 & $\therefore 000$ & $\dot{0}$ & $\dot{0} 00^{\circ}$ & 0 & 50 \\
\hline 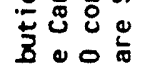 & $\frac{x}{\frac{x}{2}}$ & $\stackrel{8}{8}$ & ๓ุ & : & 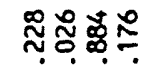 & $\stackrel{N}{N}$ & ㅊำ & $\simeq$ & 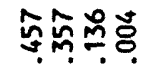 & 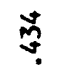 & 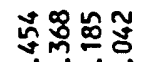 \\
\hline ए人 & & & & & Nin- & & & & & $\dot{\sim}$ & in \\
\hline 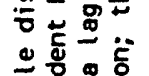 & $\sigma$ & 0 & n๖®只 & 0 & nஜ®只 & 0 & nஉュ只 & 0 & nஉ๗只 & 0 & 으용 \\
\hline 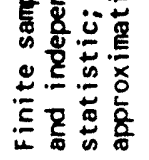 & $=$ & 요 & 응으응으 & ڤ̊ & 怘怘怘怘 & 品 & 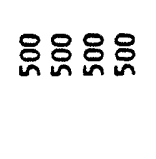 & R & 员员员员 & ळ & 잉ㅇㅇㅇㅇㅇㅇㅇ \\
\hline
\end{tabular}




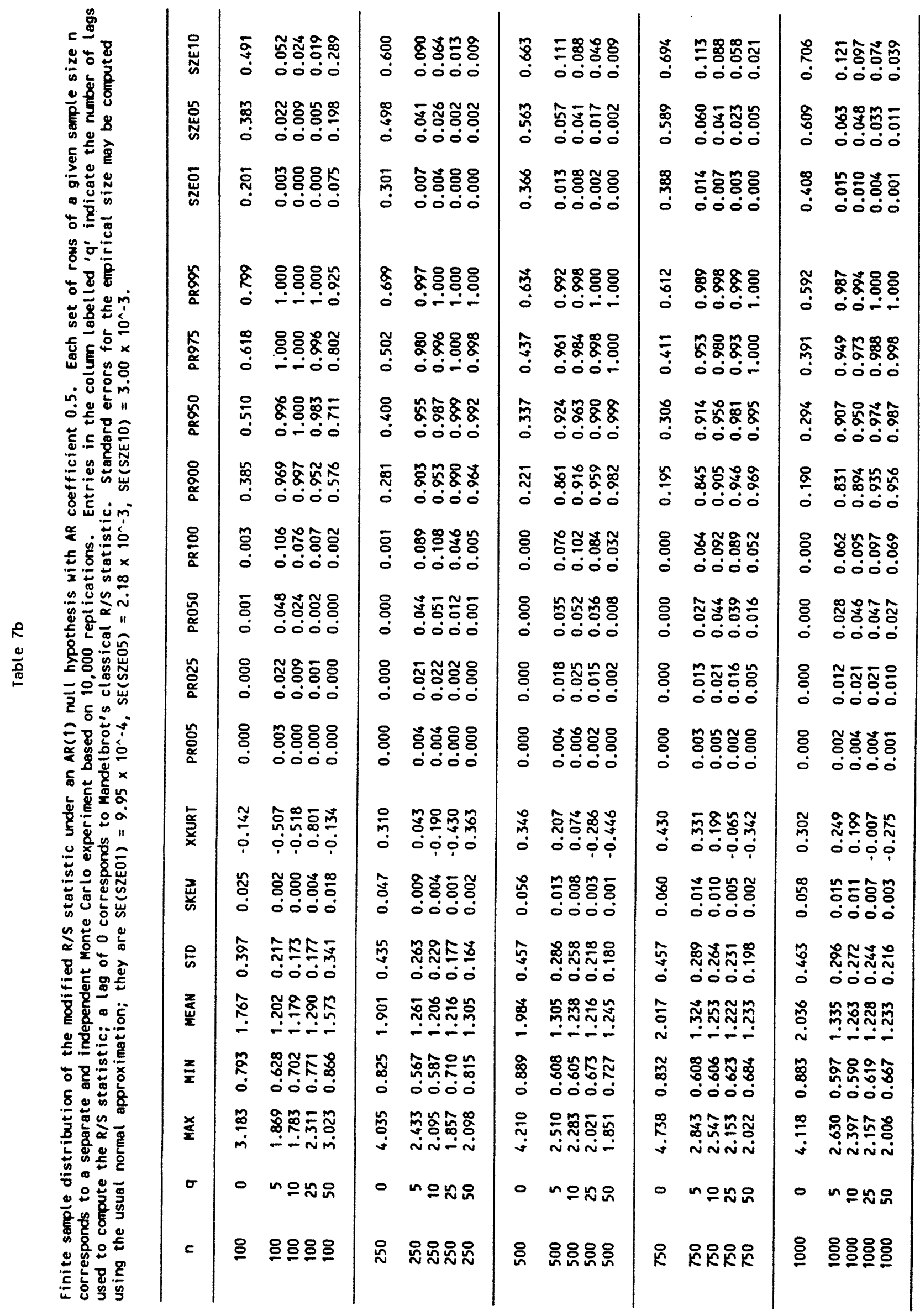




\begin{tabular}{|c|c|c|c|c|c|c|c|c|c|c|c|}
\hline 我 & $\frac{0}{\frac{9}{2}}$ & $\begin{array}{l}\text { पे } \\
\vdots \\
0\end{array}$ & 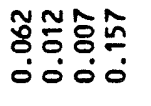 & $\stackrel{\sim}{a}$ & 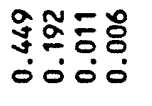 & $\begin{array}{l}\tilde{a} \\
\dot{0}\end{array}$ & 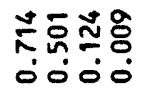 & $\stackrel{m}{q}$ & 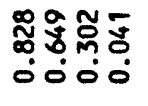 & $\stackrel{\infty}{2}$ & 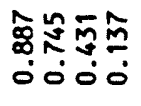 \\
\hline 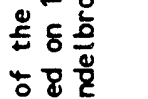 & $\begin{array}{l}\text { 旁 } \\
\frac{5}{a}\end{array}$ & $\begin{array}{l}\text { mo } \\
0 \\
0\end{array}$ & 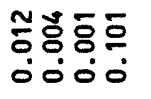 & $\begin{array}{c}\tilde{N} \\
\substack{0 \\
0 \\
0}\end{array}$ & 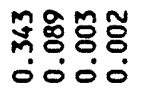 & $\begin{array}{l}8 \\
2 \\
0 \\
0\end{array}$ & 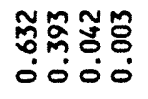 & $\begin{array}{l}\hat{\mathrm{o}} \\
\stackrel{0}{0}\end{array}$ & 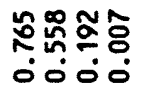 & $\stackrel{8}{2}$ & 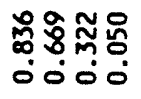 \\
\hline 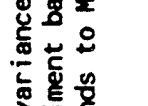 & $\overline{\bar{z}}$ & :̊. & 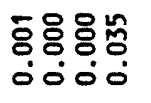 & $\hat{\imath}$ & 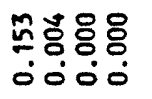 & $\begin{array}{l}\stackrel{\Xi}{0} \\
0\end{array}$ & 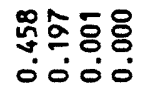 & 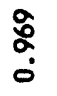 & 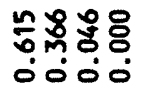 & 弁 & 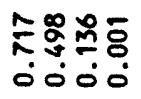 \\
\hline 봉응 & $\begin{array}{l}\text { a } \\
\frac{a}{\alpha}\end{array}$ & $\begin{array}{l}R \\
\tilde{n} \\
0\end{array}$ & 양용ㅇㅇ & 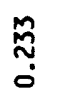 & 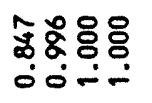 & \begin{tabular}{l}
\multirow{N}{0}{} \\
0 \\
0
\end{tabular} & 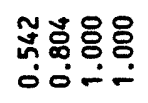 & 商 & 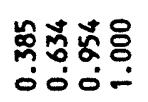 & $\stackrel{n}{0}$ & 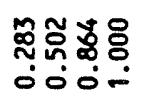 \\
\hline 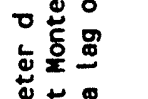 & $\begin{array}{l}\text { no } \\
\frac{\alpha}{\alpha}\end{array}$ & 总 & 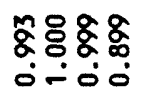 & $\frac{\mathscr{0}}{\stackrel{0}{0}}$ & 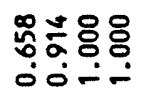 & ח̃. & 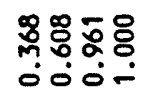 & $\stackrel{m}{\circ}$ & 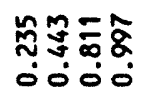 & 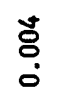 & 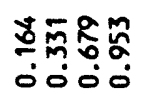 \\
\hline 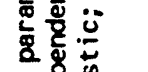 & ్ㅗㅇ & $\hat{m}$ & 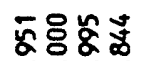 & జ̊ & 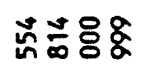 & 5 & జ్రాల్లే & $\hat{8}$ & 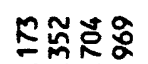 & $\tilde{\Xi}$ & 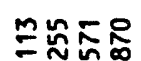 \\
\hline 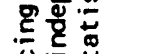 & $\bar{a}$ & 0 & & 0 & & 0 & & 0 & $0 c$ & 0 & \\
\hline & $\begin{array}{l}\text { ¿ } \\
\text { \% } \\
\frac{\alpha}{\alpha}\end{array}$ & 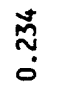 & 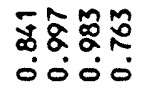 & $\begin{array}{l}\tilde{n} \\
\vdots \\
0\end{array}$ & 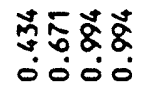 & $\begin{array}{l}\infty \\
0 \\
0\end{array}$ & 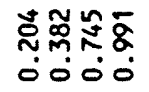 & $\begin{array}{l}\text { m} \\
\dot{0}\end{array}$ & 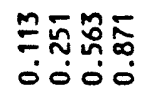 & $\begin{array}{l}\overline{8} \\
\dot{0}\end{array}$ & 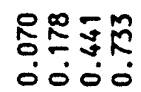 \\
\hline & $\frac{8}{\alpha}$ & m & 통 & \& & ㅎํㅇ뭉 & 8 & 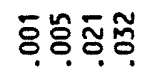 & ๕్ & $\bar{\delta}$ & 8 & 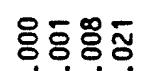 \\
\hline$\sum \approx \frac{\xi}{0}$ & & & & & & & & & & & \\
\hline 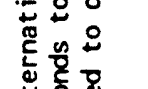 & 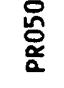 & $\begin{array}{l}\overline{8} \\
\dot{0}\end{array}$ & 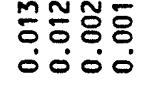 & $\begin{array}{l}8 \\
\vdots \\
0\end{array}$ & 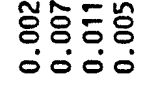 & $\begin{array}{l}8 \\
0 \\
0\end{array}$ & 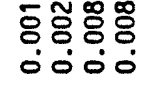 & $\begin{array}{l}8 \\
8 \\
0\end{array}$ & 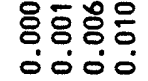 & 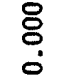 & 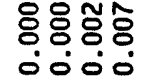 \\
\hline $\overrightarrow{0}$ & $\cong$ & $\overline{8}$ & 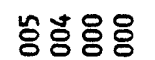 & 8 & 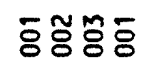 & రి & 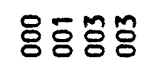 & 8 & 옹용ํㅇ & రి & 양용용 \\
\hline & $\approx$ & $\dot{0}$ & $\dot{0} \dot{0} 0 \dot{0}$ & $\dot{0}$ & $\dot{\circ 0} 0 \dot{0}$ & $\dot{0}$ & $\dot{0} 000$ & $\dot{0}$ & $00^{\circ} 0^{\circ}$ & $\dot{0}$ & $0^{\circ} 0^{\circ}$ \\
\hline & 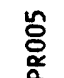 & ¿ & Бㅇㅇㅇㅇㅇ & ¿̊. & 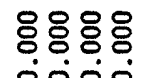 & ठ̊. & ㅇํㅇㅇํㅇํㅇ & 官 & 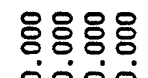 & రి & ర్రిర్రిర్రి \\
\hline & & & & & & & & & & & \\
\hline & $\frac{5}{\frac{5}{x}}$ & 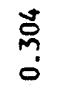 & 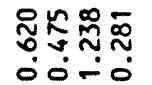 & $\underset{\tilde{0}}{\tilde{0}}$ & 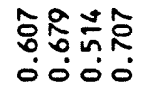 & $\frac{\pi}{0}$ & 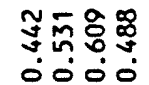 & 宽 & 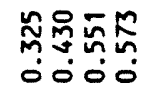 & ڤ̆ & $\begin{array}{c}0 \\
m \\
m \\
0\end{array}$ \\
\hline$\stackrel{\sigma}{\leftarrow}$ & & & & ! & إب: & כ & & & & & \\
\hline & 壳 & $\begin{array}{l}0 \\
0 \\
0 \\
0\end{array}$ & $\begin{array}{l}\bar{\delta} \bar{\delta} \\
00 \\
0\end{array}$ & $\frac{n}{0}$ & 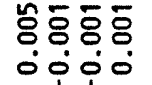 & $\begin{array}{l}\text { ले. } \\
0 \\
0\end{array}$ & $\begin{array}{l}\cong 80 \overline{0} \\
00 \\
00 \\
0\end{array}$ & \begin{tabular}{l}
8 \\
\multirow{2}{0}{} \\
0 \\
0
\end{tabular} & 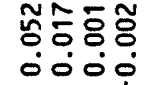 & $\begin{array}{l}\tilde{\omega} \\
0 \\
0\end{array}$ & 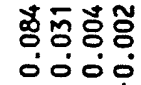 \\
\hline & e & $\frac{m}{n}$ & 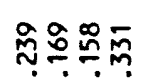 & న్ & 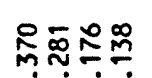 & $\frac{a}{a}$ & 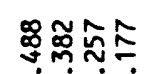 & $\ddot{\infty}$ & 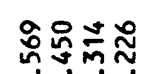 & $\stackrel{0}{0}$ & 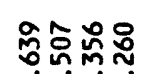 \\
\hline & & & $00^{\circ}$ & 0 & $00^{\circ} 0^{\circ}$ & 0 & $00^{\circ} 0^{\circ}$ & $\therefore$ & $00^{\circ} 0^{\circ}$ & $\therefore$ & $00^{\circ} 0^{\circ}$ \\
\hline & $\frac{\tilde{z}}{\frac{\tilde{w}}{2}}$ & $\begin{array}{l}\stackrel{\mathscr{O}}{0} \\
\stackrel{\sim}{\sim}\end{array}$ & 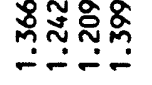 & $\begin{array}{l}\bar{g} \\
\stackrel{8}{i}\end{array}$ & 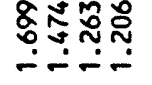 & 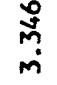 & 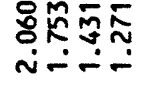 & $\begin{array}{l}\stackrel{2}{R} \\
\dot{m}\end{array}$ & 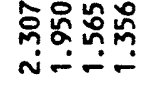 & $\frac{5}{5}$ & 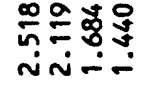 \\
\hline 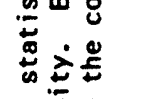 & $\frac{x}{x}$ & $\begin{array}{l}\not 8 \\
:\end{array}$ & 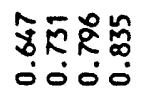 & $\begin{array}{l}\widetilde{o} \\
0 \\
0\end{array}$ & 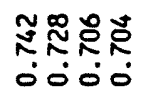 & 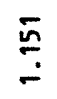 & 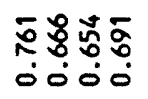 & $\hat{\sim}$ & 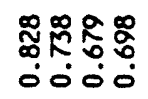 & $\stackrel{?}{9}$ & 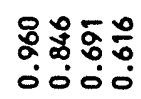 \\
\hline & $x$ & $\stackrel{\infty}{\infty}$ & 도욤요 & 8 & 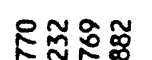 & $\tilde{n}$ & 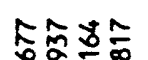 & 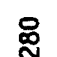 & రిస్ & ถ̊ำ & 움요으요 \\
\hline 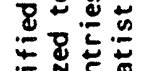 & $\bar{\Sigma}$ & $\dot{m}$ & & $\dot{n}$ & & $\dot{x}$ & & $\infty$ & $\dot{i}$ & $\alpha$ & نmiñ \\
\hline & $\sigma$ & 0 & n유요 & 0 & 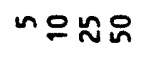 & 0 & ๓ & 0 & ํㅡㄴㅠ & 0 & ๓으쑹 \\
\hline 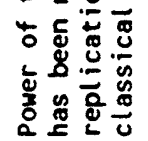 & $=$ & 요 & 응응요 & ڤ & 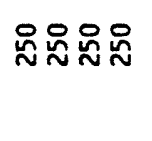 & 品 & 号品品品 & K & 负员员员 & ర్ & 응응응ㅇㅇㅇ \\
\hline
\end{tabular}




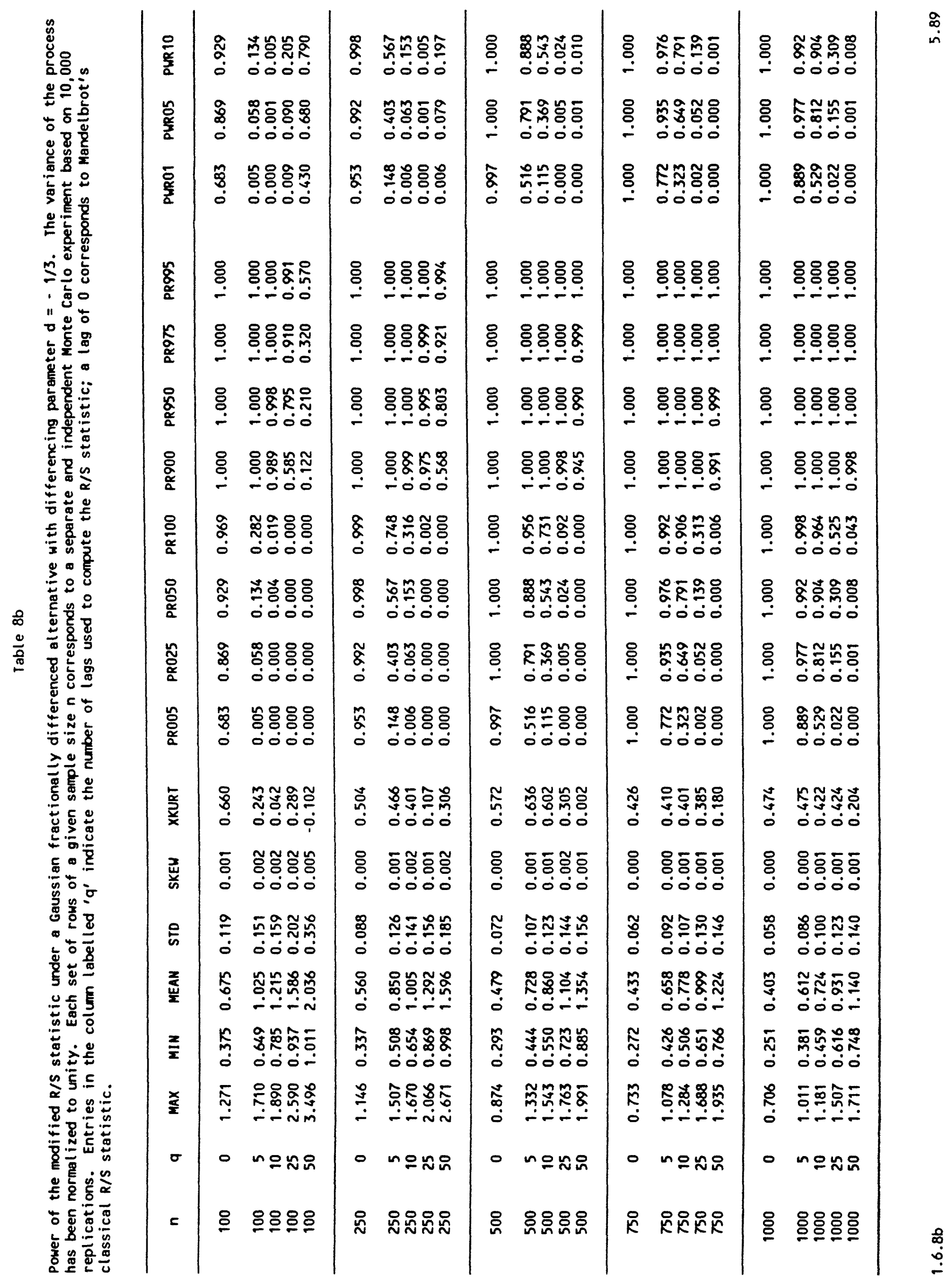




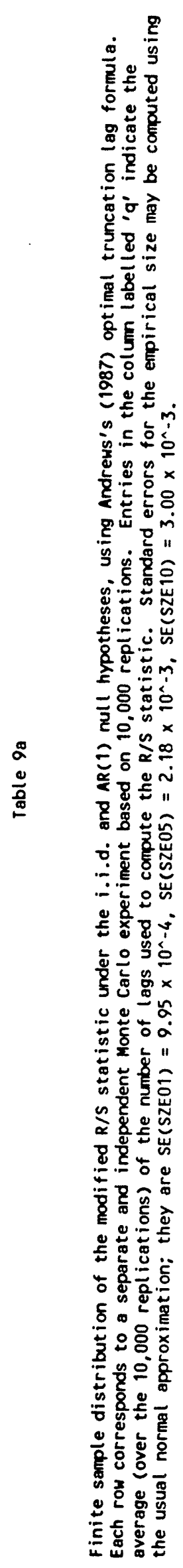

\begin{tabular}{|c|c|c|c|}
\hline$\underset{W}{\stackrel{O}{W}}$ & $\begin{array}{l}\cong \nwarrow \cong \pm \\
0000\end{array}$ & & 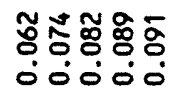 \\
\hline 噯 & 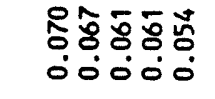 & & 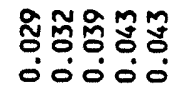 \\
\hline 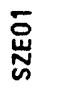 & 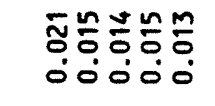 & & 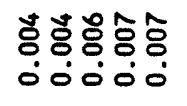 \\
\hline $\begin{array}{l}\stackrel{n}{\alpha} \\
\frac{\alpha}{a} \\
\alpha\end{array}$ & 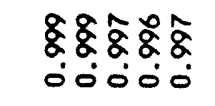 & & 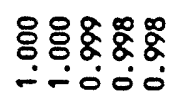 \\
\hline$\frac{\substack{\alpha \\
\alpha}}{\alpha}$ & 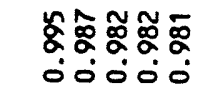 & & 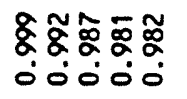 \\
\hline $\begin{array}{l}\stackrel{0}{\alpha} \\
\frac{\alpha}{\alpha}\end{array}$ & 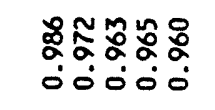 & & 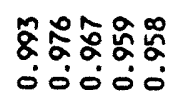 \\
\hline $\begin{array}{l}\stackrel{8}{\alpha} \\
\frac{\alpha}{\alpha}\end{array}$ & 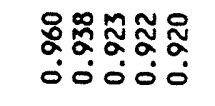 & & 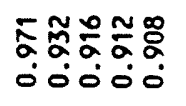 \\
\hline$\frac{8}{\frac{\alpha}{\alpha}}$ & 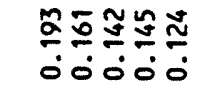 & & 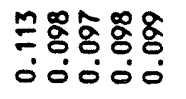 \\
\hline 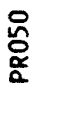 & 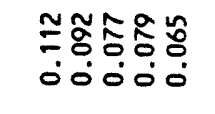 & & 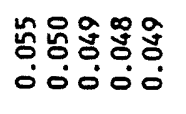 \\
\hline 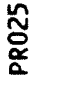 & 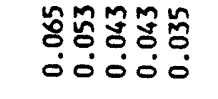 & & 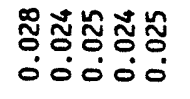 \\
\hline $\begin{array}{l}\breve{c} \\
\text { o } \\
\alpha\end{array}$ & 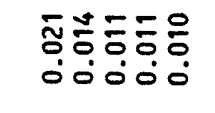 & & 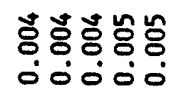 \\
\hline $\begin{array}{l}\bar{\alpha} \\
\frac{\bar{x}}{x}\end{array}$ & 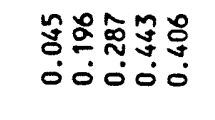 & & 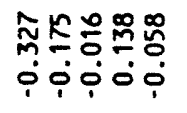 \\
\hline 胥 & 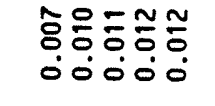 & & 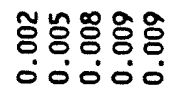 \\
\hline$\frac{0}{5}$ & 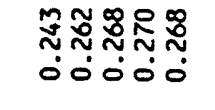 & $\ddot{\tilde{n}}$ & 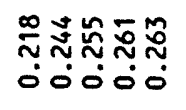 \\
\hline 吝 & 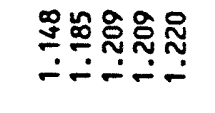 & 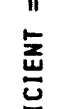 & 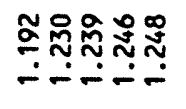 \\
\hline$\frac{x}{x}$ & 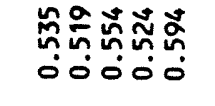 & 蒿 & 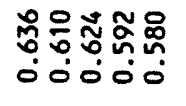 \\
\hline$\frac{x}{\frac{x}{2}}$ & 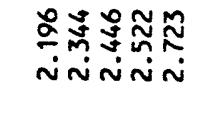 & 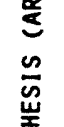 & 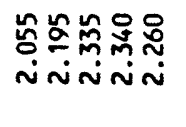 \\
\hline$\sigma$ & 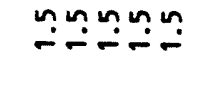 & 古 & 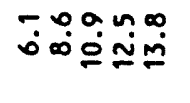 \\
\hline$\varepsilon$ & 음ㅇํํ응 & 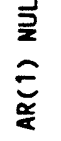 & 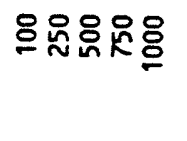 \\
\hline
\end{tabular}




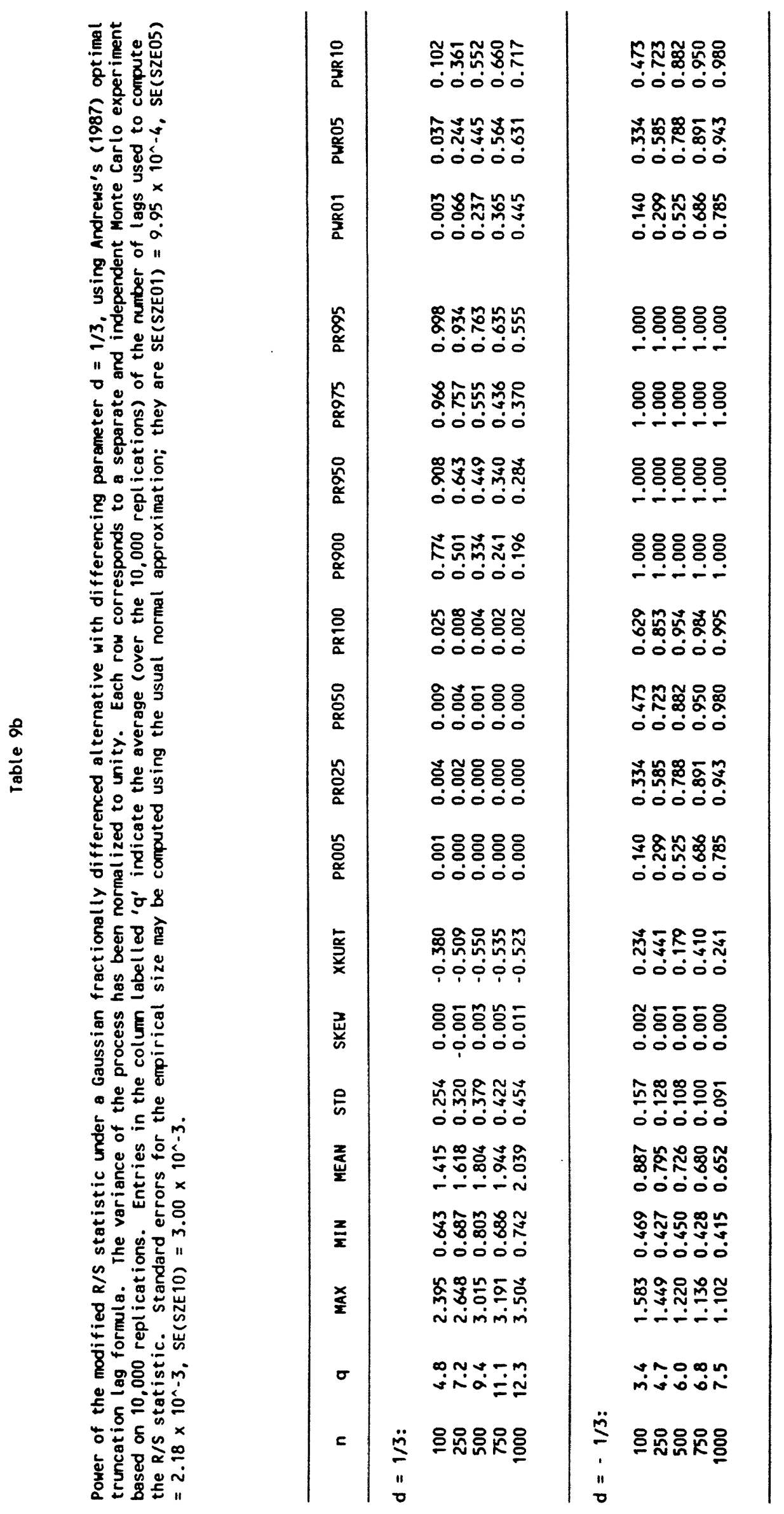

